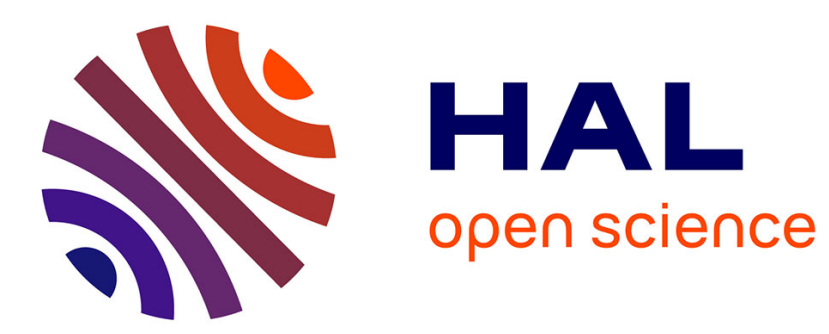

\title{
Characterization of vertical cloud variability over Europe using spatial lidar observations and regional simulation
}

\author{
Meriem Chakroun, Sophie Bastin, Marjolaine Chiriaco, Hélène Chepfer
}

\section{To cite this version:}

Meriem Chakroun, Sophie Bastin, Marjolaine Chiriaco, Hélène Chepfer. Characterization of vertical cloud variability over Europe using spatial lidar observations and regional simulation. Climate Dynamics, 2018, 51 (3), pp.813-835. 10.1007/s00382-016-3037-3 . insu-01282729

\section{HAL Id: insu-01282729 \\ https://hal-insu.archives-ouvertes.fr/insu-01282729}

Submitted on 22 Mar 2016

HAL is a multi-disciplinary open access archive for the deposit and dissemination of scientific research documents, whether they are published or not. The documents may come from teaching and research institutions in France or abroad, or from public or private research centers.
L'archive ouverte pluridisciplinaire HAL, est destinée au dépôt et à la diffusion de documents scientifiques de niveau recherche, publiés ou non, émanant des établissements d'enseignement et de recherche français ou étrangers, des laboratoires publics ou privés. 


\section{Characterization of vertical cloud variability over Europe using}

2 spatial lidar observations and regional simulation

(1) Université Versailles St-Quentin, Université Paris-Saclay; Sorbonne Universités, UPMC Univ. Paris 06 ; CNRS/INSU, LATMOS-IPSL, Guyancourt, France.

(2) Laboratoire de Météorologie Dynamique, IPSL, Université Paris 6, Centre National de la Recherche Scientifique, Paris, France.

LATMOS

11 bd d'Alembert

78280 Guyancourt, France

\section{ACKNOWLEDGMENTS}

This work is a contribution to the EECLAT project through Les Enveloppes Fluides et l'Environnement / Institut National des Sciences de l'Univers and Terre, Océan, Surfaces Continentales, Atmosphère / Centre National d'Etudes Spatiales supports and to the HyMeX program through INSU-MISTRALS support, and the MedCORDEX program. Simulation was performed using Grand Equipement National de Calcul Intensif with granted access to the HPC resources of Institut du Développement et des Ressources en Informatique Scientifique (under allocation i2011010227). The authors would like to thank Climserv team for computing and storage resources. Marjolaine Chiriaco research is directly supported by Centre National d'Etudes Spatiales. The authors wish to thank Florian Rouvière, Gregory Césana, and Vincent Noël for their contribution to this work. 


\section{TABLE OF CONTENTS}

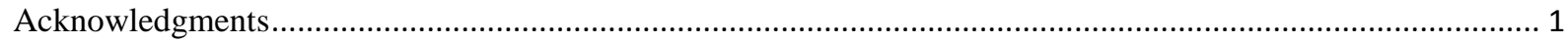

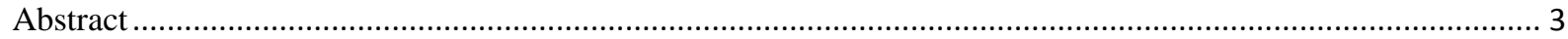

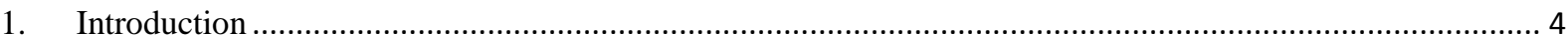

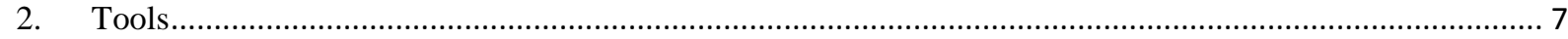

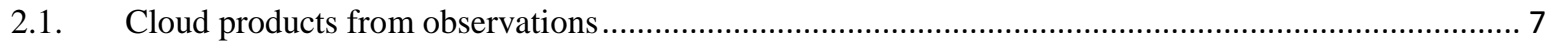

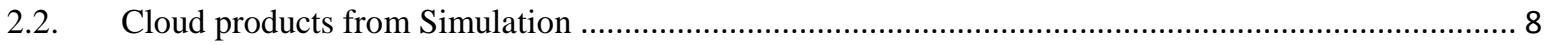

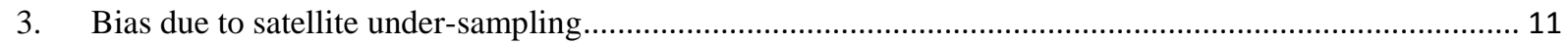

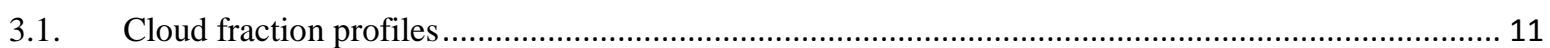

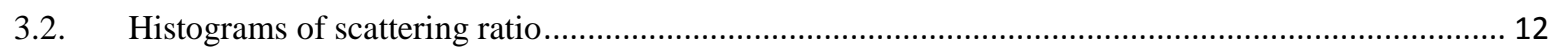

4. Characterization of the seasonal cycle and ability of the model to reproduce it ....................................... 14

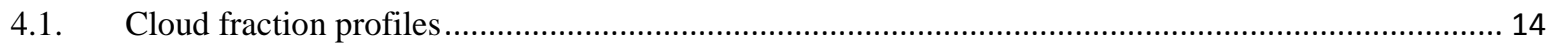

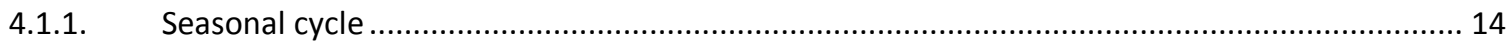

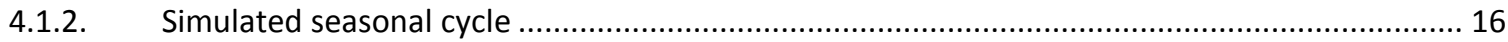

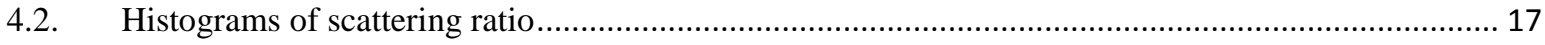

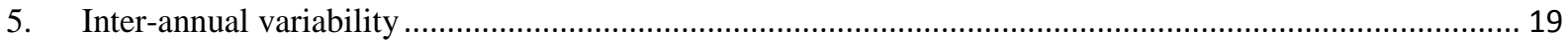

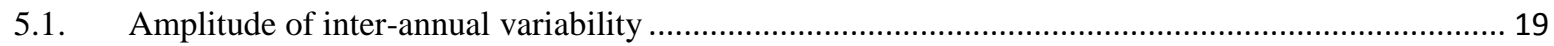

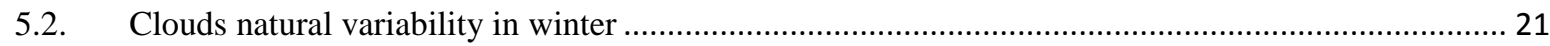

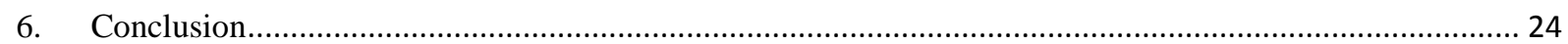

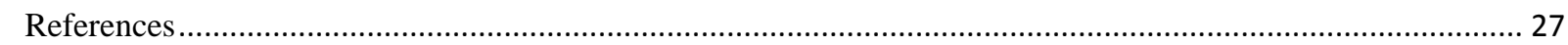

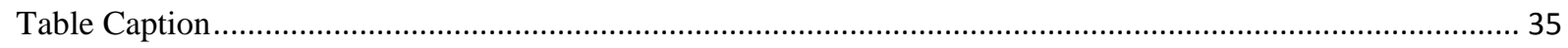

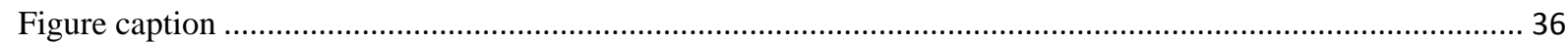




\section{ABStRACT}

In this paper we characterize the seasonal and inter-annual variabilities of cloud fraction profiles in both observations and simulation since they are critical to better assess the impact of clouds on climate variability. The spaceborne lidar onboard CALIPSO, providing cloud vertical profiles since 2006, is used together with a 23-year WRF simulation at $20 \mathrm{~km}$ resolution. A lidar simulator helps to compare consistently model with observations. The bias in observations due to the satellite under-sampling is first estimated. Then we examine the vertical variability of both occurrence and properties of clouds. It results that observations indicate a similar occurrence of low and high clouds over continent, and more high than low clouds over the sea except in summer. The simulation shows an overestimate (underestimate) of high (low) clouds comparing to observations, especially in summer. However the seasonal variability of cloud vertical profiles is well captured by WRF. Concerning inter-annual variability, observations show that in winter, those of high clouds is twice the low clouds one, an order of magnitude that is is well simulated. In summer, the observed inter-annual variability is vertically more homogeneous while the model still simulates more variability for high clouds than for low clouds. The good behavior of the simulation in winter allows us to use the 23 years of simulation and 8 years of observations to estimate the time period required to characterize the natural variability of the cloud fraction profile in winter, i.e the time period required to detect significant anomalies and trends.

Keywords: lidar, clouds, simulation, Europe, natural variability 


\section{INTRODUCTION}

Improving our understanding of the internal variability of the European climate is a necessary step to get more reliable prediction of the temperature evolution in the next two decades over Europe (Hawkins and Sutton 2009). Actually, using Coupled Model Intercomparison Project (CMIP3) models and despite the fact that these models may overestimate natural decadal fluctuations, Hawkins and Sutton (2009) show that the climate internal variability is the most important source of uncertainty to predict the regional temperature in the next two decades. By comparing different regions of the world, they also showed that this uncertainty is maximal over Europe compared to other regions. For prediction times of many decades (more than 2 decades), the uncertainty on the future climate prediction is no more dominated by the lack of knowledge on the inter-annual variability, but by the uncertainty of the model itself (eg. the difficulty of the model to reproduce the actual state of the atmosphere) which then becomes the dominant contribution to the uncertainty in the prediction of the future climate at regional scale. The authors suggest that using observations of the current climate state may help to better understand the inter-annual variability of the climate system and to reduce model defaults; doing so may contribute to reduce uncertainties in the prediction of the evolution of the climate at regional scale.

At first order, temperature over Europe is driven by the large-scale atmospheric circulation (e.g. Rojas et al. 2013; Xoplaki et al. 2004). In particular, in winter and summer, European climate is characterized by the succession of four weather regimes resulting from the relative location of three pressure centers: the Icelandic low, the Azores high and the continental highs and lows (Yiou et al. 2007; Cassou et al. 2004, 2005; Vautard 1990). Southern Europe and Mediterranean Basin climates are influenced by the North Atlantic regimes but are also under the influence of the Genoa depression and the Atlas lee depression (Reiter 1975), which drive air masses from the south.

However, large-scale circulation cannot explain all the variability. According to Yiou et al. (2007) temperature anomalies are more and more often influenced by other factors. Clouds are one of these factors and play a major role in the natural temperature variability due to their radiative effects. Chiriaco et al. (2014) showed the spatial correlation between the area of positive temperature anomaly which occurred during July 2006 over Western Europe and the lack of low clouds, using satellite observations. Using observations over 1984-2007, Tang et al. (2012) suggest that clouds over Europe are better indicator of summer maximum temperature changes than the proxies of soil moisture anomalies, and that the summer temperature increase is correlated with total cloud cover 
decrease. However, clouds remain an important source of uncertainties in our understanding of climate variability (Soden and Held 2006) due to the complex cloud feedbacks with surface and boundary layer, orography and tropospheric environment (air entrainment and humidity). These processes influence the internal variability of climate response and enhance the model uncertainties. Despite these uncertainties, several studies using models have investigated the role of clouds on the present and future climate over Europe. They suggest the increasing of future summer temperature variability particularly for central Europe (Lenderink et al. 2007), a future annual precipitation increase over northern Europe (Kjellström et al. 2011) and a decrease trend of the cloud cover in summer over Europe (Tang et al. 2012). Other authors have shown how model biases in present climate influence the model response to greenhouse gases forcing. For instance, Boé and Terray (2014) show that climate models with surface temperature strongly sensitive to cloudiness simulate a larger future decrease of cloud cover than other models (over land, in summer). Lenderink et al. (2007) studied temperature variability and the surface energy budget over control period (1961-1990) and future climate (2071-2100) in an ensemble of regional climate models and show that i) temperature variability is overpredicted in the control simulations; ii) temperature variability is very correlated with surface energy budget variability in the models; iii) clouds and radiation are critical to determine the climate sensitivity on Western Europe in summer in regional models.

The goal of this study is to characterize and understand clouds natural variability in the current climate to better assess its effect on European climate characteristics (future work). We will focus on the vertical distribution of clouds because: (i) the clouds radiative effect depend on the vertical distribution of microphysical and macrophysical properties of clouds (Stephens 2005), and (ii) the vertical distribution of clouds is a much more robust signature of climate variability than vertically integrated variables (total cloud cover or radiative fluxes) (Chepfer et al. 2014). Three main questions are then addressed in the current paper: (1) What is the seasonal variability of the cloud vertical distribution over Euro-Mediterranean area? (2) What is its inter-annual variability? (3) Are simulations able to reproduce the amplitude of these variabilities?

To address these questions we used Cloud Aerosol Lidar and Infrared Pathfinder Satellite Observations (CALIPSO) that provides very detailed vertical description of clouds' distribution (Winker et al. 2003) since 2006. This study only focuses on nighttime profiles since cloud detection is more accurate than during daytime (Winker et al., 2009) (see section 2.1). Eight years (since 2006) are a priori not sufficient to cover the entire natural variability. Moreover, the satellite under-sampling of the Europe-Mediterranean area due to the sunsynchronous orbit could be an issue for covering the cloud variability. Then, we use a simulation in addition to 
CALIPSO observations. Requirements for the simulation are (i) covering the Euro-Mediterranean region, (ii) a good spatio-temporal resolution in order to take into account the complex terrain and the influence of the different air masses that characterize the area of study and which influence the cloud formation, (iii) at least 20 years as it is the period where the internal variability is the principal source of uncertainty in the simulation of European climate (Hawkins and Sutton 2009), iv) a nearly 'perfect' dynamics to better evaluate and estimate the fluctuations linked to clouds. A WRF (Weather Research and Forecast Model; Skamarock and Klemp 2008) simulation performed in the framework of HyMex (HYdrological cycle in Mediterranean EXperiment; Drobinski et al. 2014) and MED-CORDEX (Mediterranean COodinated Regional climate Downscaling EXperiment; Ruti et al. 2015) programs is used as it presents these characteristics: 23 years with outputs every 3 hours, $20 \times 20 \mathrm{~km}^{2}$ horizontal resolution, and the nudging option towards ERA-interim reanalysis for wind, temperature and humidity above the boundary layer. Also, the same diagnosis of clouds is needed for both observations and simulation. Since WRF simulates concentration of liquid water, snow and ice which are not directly comparable with the lidar, a lidar simulator (Chiriaco et al. 2006; Chepfer et al. 2008) developed for Global Circulation Models (GCMs) in Cloud Feedback Model Intercomparison Project (CFMIP) Observation Simulator Package (COSP, Chepfer et al. 2008) has been adapted to WRF and used in this study.

These tools are presented in Sect. 2. An important issue for this regional climate variability study is the satellite under-sampling effect: this issue is addressed in Sect. 3 using two different samplings of the simulation. Also, the vertical distribution of clouds has been carefully evaluated in GCMs, in particular with the GCM-Oriented CALIPSO Cloud Product (GOCCP; Chepfer et al, 2008; Cesana and Chepfer 2012) developed to evaluate clouds representation in GCMs. But it has not been evaluated in regional simulation except for some case studies (e.g. Chaboureau et al. 2012 for some convective precipitating clouds over western Europe; Chiriaco et al. 2006 for some cirrus clouds in the Paris area). Then, the WRF/MedCordex simulation's representation of the clouds' vertical structure over Euro-Mediterranean area and in particular its ability to reproduce the amplitude of the seasonal variability is addressed in Sect. 4. In sect 5, the inter-annual variability of cloud profiles is studied in both observations and simulation: the ability of the model to detect climate extremes, and the question of the number of years required to cover the entire natural variability are addressed. Conclusions and prospects of this work are presented in Sect. 6. 


\section{TOOLS}

156

157

158

159

\subsection{CLOUD PRODUCTS FROM OBSERVATIONS}

CALIOP is a two-wavelength polarization-sensitive lidar that provides high-resolution vertical profiles of clouds. This study is based on the 532-nm channel in parallel polarization analysis. This wavelength is in the visible spectrum making the signal-to-noise ratio reduced during daytime due to solar radiations, affecting the detection of daytime clouds (Winker et al. 2009). Thus, this study only focuses on nighttime profiles. It corresponds to a satellite overpass between 23 UTC and 03 UTC for this region. Results can be different for daily clouds, in particular for low clouds $(\mathrm{z}<3.2 \mathrm{~km}$ corresponding to $\mathrm{P}>680 \mathrm{hPa}$ ) that have an important diurnal cycle. CALIOP's vertical resolution is $30 \mathrm{~m}$ from ground to $8.2 \mathrm{~km}$ of altitude and $60 \mathrm{~m}$ above. Its horizontal resolution is $330 \mathrm{~m}$. Cloud products used in this study are the GOCCP products. They are specially developed for comparison with models, in particular GCM. In GOCCP, while the original horizontal resolution of CALIOP is kept, the original vertical resolution is modified and the profiles are vertically averaged on a GCM typical vertical resolution of $480 \mathrm{~m}$ (Chepfer et al. 2010). Here, they are adapted for comparison with regional model simulation. Two cloud products are defined:

- $\mathrm{SR}_{\mathrm{GOCCP}}(\mathrm{z})$ is based on Scattering Ratio (SR) values, which highlight the contribution of particles (condensed water or aerosols) to the lidar signal (Annex 1, eq1). SR is equal to 1 in absence of clouds and aerosols. SR $>1$ traduces the existence of particles; it is either aerosols or condensed water. The more optically thick clouds, the higher SR values. When the lidar signal is fully attenuated by optically thick clouds, the layers below are obscured and SR values at lower levels become very low $(<0.01)$. $\mathrm{SR}_{\mathrm{GOCCP}}(\mathrm{z})$ keeps the GOCCP original resolution horizontally and vertically (over 34 levels from the ground).

$-\mathrm{CF}_{\mathrm{GOCCP}}(\mathrm{z})$ is the Cloud Fraction computed from SR profiles at $330 \mathrm{~m}$ horizontal resolution over the $20 \times 20$ $\mathrm{km}^{2}$ horizontal resolution of the simulation (see Sect. 2.2) over the 34 vertical layers. Figure 1 shows the model grid and the number of CALIPSO nighttime overpasses during June-July-August (JJA) 2008 over each grid point. With this resolution, some parts are never covered by CALIPSO and the overpass number on the covered grid-boxes varies between 3 and 6 over one season but the number of observed profiles over one grid point is increased by the horizontal resolution of $330 \mathrm{~m}$. Cloud detection is based on SR thresholds following Chepfer et al. (2008, 2010): $0.01<\mathrm{SR} \leq 1$ clear, $1.2<\mathrm{SR}<5$ (existence of particles, could be optically thin clouds or 
aerosols), and the threshold of cloud detection is set to $5(\mathrm{SR} \geq 5)$. These thresholds are used for each profile at each vertical level (Fig. 10 annex 1). The cloud fraction over a gridbox is then the percentage of cloudy profiles $(\mathrm{SR}(\mathrm{z}) \geq 5)$ by the total number of profiles that are not fully attenuated $(\mathrm{SR}(\mathrm{z}) \geq 0.1)$.

In the current study, $\mathrm{SR}_{\mathrm{GOCCP}}$ and $\mathrm{CF}_{\mathrm{GOCCP}}$ profiles observed throughout the period $06 / 2006$ to $12 / 2011$ are used, as it is the common period with the simulation (Sect. 2.2).

\subsection{CLOUD PRODUCTS FROM SIMULATION}

\subsubsection{SIMULATION SET-UP}

A 23-year simulation with the WRF model of the National Center for Atmospheric Research (NCAR) (Skamarock and Klemp 2008) was performed at $20 \times 20 \mathrm{~km}^{2}$ resolution over the Mediterranean basin in the framework of COordinated Regional climate Downscaling Experiment (CORDEX; Giorgi et al. 2009. Note that MED-CORDEX is the Mediterranean focus of CORDEX; Ruti et al. 2015) and HYMEX programs (Drobinski et al. 2014). It performs a dynamical downscaling of the ERA-interim data (Dee et al. 2011) over the period 19892011. The model has 28 sigma-levels in the vertical. A complete set of physics parameterizations is used: the Single-Moment 5-class microphysical scheme (WSM5; Hong et al. 2004), the Kain-Fritsch convection scheme (Kain 2004), the YonSei University (YSU) planetary boundary layer (PBL) scheme (Noh et al. 2003) and a parameterization based on the similarity theory (Monin and Obukhov 1954) for the turbulent fluxes. The radiative scheme is based on the Rapid Radiative Transfer Model (RRTM) (Mlawer et al. 1997) and the Dudhia (1989) parameterization for the longwave and shortwave radiations, respectively. The lower boundary conditions of the WRF model are provided by the land surface model (LSM) Rapid Update Cycle (RUC) (Smirnova et al. 1997, 2000). Nudging above the boundary layer is used in order to avoid the small-scale variations to generate a large-scale that would diverge from the observed large-scale structures inside the limited area (Stauffer and Seaman 1990; Salameh et al. 2010; Omrani et al. 2013). Hence it allows us to compare the structure of clouds with the same large-scale environment.

This simulation has been already used for several studies and has been evaluated against data for temperature (e.g Chiriaco et al. 2014; Stefanon et al. 2014), precipitation (e.g Flaounas et al. 2013, 2014; Lebeaupin-Brossier et al. 2015; Vaittinada et al. 2015) and wind (Omrani et al. 2014).

Cloud outputs are mixing ratios of ice, snow and liquid and are interpolated on the same vertical resolution as 
GOCCP between the ground and $16 \mathrm{~km}$, which corresponds to 34 levels. They are available every $3 \mathrm{~h}$.

\subsubsection{LIDAR SIMULATOR AND DATASETS}

To compare WRF outputs with CALIPSO lidar observations, we use a methodology similar to the one followed by Chepfer et al. (2008) and Cesana and Chepfer (2012) comparing CALIPSO observations with a GCM. Also we define two datasets to better assess the issue of sampling. The methodology then consists in i) extracting two different datasets of WRF vertical profiles: one that uses the total grid of the simulation and another one using the satellite horizontal and temporal resolutions (see details below) ii) from these extracted profiles, computing the lidar profiles that would be observed by CALIPSO if the satellite were flying above the simulated atmosphere (Chepfer et al. 2008), iii) using the same SR bins as the ones used for GOCCP, iv) computing the cloud fraction from the simulated SR profiles as the percentage of SR ( $\mathrm{z}) \geq 5$ per grid-box as done to produce $\mathrm{CF}_{\mathrm{GOCCP}}$ (see Sect. 2.1.).

The first dataset is obtained by extracting one profile per night, at $00 \mathrm{UTC}$, over each grid box. It corresponds to about $2.10^{6}$ profiles for one season. The covered period is 1989-2011. The second dataset corresponds to the profiles that are coincident with CALIPSO tracks, at the closest time of CALIPSO overpass (i.e either 00 or 03 UTC). As CALIPSO horizontal resolution is $330 \mathrm{~m}$ while the WRF one is $20 \mathrm{~km}$, the number of CALIPSO profiles that fall into one WRF grid-box varies between 0 (Fig. 1a) and 85 (depending on the fact the track crosses the box along its diagonal or only at its corner or not at all). The WRF profiles are duplicated to obtain a CALIPSO like track with the same number of CALIPSO profiles over a grid-box, to give to each grid box the corresponding weight. However, we have tested the extraction of cloud profiles without duplicating the profiles (using only one WRF profile per grid-box that is crossed over) and the differences are very negligible for the current study. Over one season, the number of profiles of this second dataset is about $8.10^{7}$ (obtained from $5.10^{4}$ profiles, before duplicating). The available period is 2006-2011.

A lidar simulator is associated to these WRF outputs. It consists on computing the lidar signal (equation 2 in annex 1) from WRF outputs considering the effective radius $r$ and size distribution $n(r, z)$ of each meteor (here liquid, ice and snow). Since these parameters are not direct outputs of the model and since the simulator is offline the model, they are computed from the mixing ratio of ice (Qi), snow (Qs) and liquid (Q1) (outputs of the model) using the microphysical equations used in the parameterization (here WSM5). WRF outputs (Qi, Q1, Qs, pressure and temperature) are interpolated on a regular vertical grid first and then the lidar signal is computed 
giving SR profiles for the two datasets. Afterwards, cloud fraction profiles are computed following the same method as for observations (Sect. 2.1). The variables obtained are $\mathrm{SR}_{\mathrm{WRF}+\operatorname{sim}}{ }^{\mathrm{T}}(\mathrm{z})$ and $\mathrm{CF}_{\mathrm{WRF}+\operatorname{sim}}^{\mathrm{T}}(\mathrm{z})$ for the first dataset and $\mathrm{SR}_{\mathrm{WRF}+\mathrm{sim}}(\mathrm{z})$ and $\mathrm{CF}_{\mathrm{WRF}+\mathrm{sim}}(\mathrm{z})$ for the second dataset, both over period 2006-2011 (Tab. 1). The exposant $\mathrm{T}$ is for the total simulation dataset.

Figure $2 \mathrm{a}$ is a randomly picked scene showing an example of the vertical profiles of $\mathrm{SR}_{\mathrm{GOCCP}}(\mathrm{z})$ along a CALIPSO track (2009-01-19 at night) between $30^{\circ} \mathrm{N}$ and $50^{\circ} \mathrm{N}$ latitudes and $3^{\circ} \mathrm{E}$ and $5^{\circ} \mathrm{E}$ longitudes. The same scene is represented in Fig. $2 b$ with the simulated total condensed water mixing ratios, while Fig. 2c shows $\mathrm{SR}_{\mathrm{WRF}+\operatorname{sim}}(\mathrm{z})$. The red shadows in Figs. 2a-c show the cloud structures, the dominant blue represents the clear sky and the dark blue indicates that the signal is fully attenuated. As the model does not simulate aerosols, the boundary layer is not properly represented in the simulated profiles (Figs. $2 \mathrm{~b}$ and c).

Clouds detected by CALIOP shown in Fig. 2a are simulated by the model most of the time (Fig. 2.b and c) despite few differences (around $32^{\circ} \mathrm{N}$, around $49^{\circ} \mathrm{N}$ ). In this case study, the vertical cloud structure is less variable in the simulation than in the observations. This result of bigger and more persistent clouds in terms of occurrence and lifetime in regional simulation over Europe is expected and has been shown in previous studies with mesoscale models: e.g the evaluation of some cirrus clouds case studies (1-2 months) of the fifth-generation Pennsylvania State University-NCAR Mesoscale Model (MM5) with ground-based measurements over France (Chiriaco et al. 2006) and over Europe with Ice, Cloud and land Elevation Satellite (IceSat) lidar observations (Chepfer et al. 2007).

The comparison between Fig. $2 b$ and $c$ illustrates the importance of comparing lidar observations with a similar simulated signal:

- the lidar signal can be fully attenuated, masking lower clouds even if they are simulated: for instance at $43^{\circ} \mathrm{N}$, between 5 and $7 \mathrm{~km}$, high mixing ratio are simulated, while $\mathrm{SR}(\mathrm{z})$ value is less than 0.01 .

- a weak mixing ratio may be associated to significant SR value (e.g. between 40 and $41^{\circ} \mathrm{N}$ or between 46 and $\left.48^{\circ} \mathrm{N}\right)$. It's due to the fact that SR (z) is a signature of the optical depth and optical properties of clouds (type of particles, size, concentration), and not only of the particles concentration (Chepfer et al. 2013). 
In the current study, these tools are used to characterize the seasonal and interannual variabilities of the vertical structure of clouds over the Euro-Mediterranean region. As shown by Fig. 1, the orbit of the satellite does not allow us to evaluate the spatial variability of clouds at these spatial and time scales.

Before using the tools for inter-annual variability studies, two steps are necessary: (i) evaluate the biases caused by the satellite under-sampling (Sect. 3), and ii) evaluate the biases of the modeled clouds (Sect. 4).

\section{BIAS DUE TO SATELLITE UNDER-SAMPLING}

The number of satellite tracks over one season is limited in a grid-box. Figure 1a shows that CALIPSO does not overfly all the grid elements at $20 \times 20 \mathrm{~km}^{2}$ resolution, and that the maximum number of overpasses over one grid-box is 6 in one given season. To study cloud variability at this spatial scale and resolution, it is then necessary to cumulate enough profiles temporally or spatially. This section aims at quantifying the bias in the cloud variability due to the satellite under-sampling, depending on the number of seasons cumulated. 5

\subsection{CLOUD FRACTION PROFILES}

The effect of satellite under-sampling on cloud fraction profiles is examined here by using only the simulation, as a complete sampling is by definition not available in observations. Comparing complete sampling and satellite sampling of the same dataset (here the simulation) will allow only focusing on biases due to the sampling (so not also the biases of the simulation). Black lines (computed over around $2.10^{6}$ profiles) in Fig. 3 represent $\mathrm{CF}_{\mathrm{WRF}+\operatorname{sim}}^{\mathrm{T}}(\mathrm{z})$, cloud fraction profiles extracted every $00 \mathrm{UTC}$ over the entire domain, i.e one profile per grid box. They are compared to the red lines (computed over $5.10^{4}$ profiles) representing $\mathrm{CF}_{\mathrm{WRF}+\operatorname{sim}}(\mathrm{z})$, cloud fraction profiles following the CALIPSO sampling, i.e either 0 profile over a grid box or several profiles duplicated to get the same number of WRF profiles than CALIPSO profiles in this grid box. Cloud fraction profiles are computed from the WRF/MED-CORDEX simulation using the lidar simulator (Sect. 2.2.b) and averaged over the domain and over the years (2006-2011) for each season. 
For the four seasons (Fig. 3), CALIPSO sampling does not generate real bias on lidar cloud fractions, $\mathrm{CF}_{\mathrm{WRF}+\operatorname{sim}}(\mathrm{z})$ being very similar to $\left.\mathrm{CF}_{\mathrm{WRF}+\operatorname{sim}^{\mathrm{T}}}{ }^{\mathrm{T}} \mathrm{z}\right)$. Note that the differences are only observable for high levels (z > $6.5 \mathrm{~km}$ corresponding to pressure $\mathrm{P}<440 \mathrm{hPa}$ ) because of the small cloud fraction values below $6 \mathrm{~km}$ (Fig. 3). This aspect will be discussed in section 4. For high levels, the maximum errors of cloud fraction for one layer are around $3 \%$ over one season (Tab. 2).

The absolute value of the relative errors averaged vertically over high levels are smaller in winter (5\%) and spring $(7 \%)$ than in fall $(9 \%)$ and summer $(21 \%)$. The errors may seem large in fall and summer; it is due to the small vertical shift of the profiles, which enhances the relative difference between the two profiles at levels where the cloud fraction is not maximal. The maximum of difference in cloud fraction is approximately the same for the four seasons and less than $5 \%$. This shift of high clouds level due to satellite under-sampling may be linked to the occurrence of deep convection happening in summer and fall inducing local mesoscale clouds (Funatsu et al., 2009) that are more likely to be missed by the satellite because of their short lifetime and small spatial extent (Rysman et al., 2013).

For mid and low levels, the values of cloud fraction differences between $\mathrm{CF}_{\mathrm{WRF}+\operatorname{sim}}(\mathrm{z})$ and $\mathrm{CF}_{\mathrm{WRF}+\operatorname{sim}}{ }^{\mathrm{T}}(\mathrm{z})$ are very small (around $0.1 \%$ ). The average relative errors at these levels remain weak though: $6 \%$ in fall, $9 \%$ in spring and $11 \%$ in summer. Notice that in winter, the biases for mid-levels reach $13 \%$ related to a vertical shift at $6 \mathrm{~km}$. The origin of the underestimate of low and mid clouds is discussed in the next section.

\subsection{HISTOGRAMS OF SCATTERING RATIO}

To go further in details and have an idea about the physical properties of clouds overestimated/ missed with the CALIPSO under-sampling, 3D SR histograms are analyzed (Fig. 4). These histograms provide detailed vertical information on cloud optical and physical properties. Two simulated SR histograms are compared: (1) the distributions of SR(z) occurrence for each altitude and SR bin when cumulating SR profiles following CALIPSO tracks $\left(\operatorname{SR}_{\mathrm{WRF}+\operatorname{sim}}(\mathrm{z})\right.$, Fig 4a); (2) the same but with the full resolution of the simulation $\left(\mathrm{SR}_{\mathrm{WRF}+\operatorname{sim}}{ }^{\mathrm{T}}(\mathrm{z})\right.$, Fig $\left.4 \mathrm{~b}\right)$.

In each histogram, the first bar is the percentage of fully attenuated profiles $(0 \leq \operatorname{SR}(\mathrm{z})<0.01)$ and the second bar corresponds to clear sky profiles $(0.01 \leq \mathrm{SR}(\mathrm{z})<1.2)$. The $3^{\text {rd }}$ and $4^{\text {th }}$ bars are for unclassified profiles $(1.2 \leq$ $\operatorname{SR}(z)<5)$. The subsequent bars are for cloudy profiles $(\operatorname{SR}(z) \geq 5)$. Figures $4 \mathrm{a}$ and $\mathrm{b}$ are very similar: great 
attenuation below $7 \mathrm{~km}$, many high clouds with $5 \leq \mathrm{SR}(\mathrm{z})<20$ and some low level clouds with $40 \leq \mathrm{SR}(\mathrm{z})<60$. The similitudes show that the total SR distribution is not significantly affected by the sampling of the satellite.

Figure $4 \mathrm{c}$ shows the absolute difference between Fig. $4 \mathrm{a}$ and $4 \mathrm{~b}$. In average, the differences due to CALIPSO sampling for $1.2 \leq \mathrm{SR}(\mathrm{z})<20$ below $7 \mathrm{~km}$ and for the $\mathrm{SR}(\mathrm{z})$ values $\geq 20$ (all altitudes) are under $0.25 \%$ (grey shade). For $5 \leq \mathrm{SR}(\mathrm{z})<20$, the differences at high levels are around $2 \%$. The largest differences occur for the $0.01 \leq \mathrm{SR}(\mathrm{z})<3$ (clear sky and unclassified profiles) at altitudes between 12 and $14 \mathrm{~km}$.

Figure $4 \mathrm{c}$ is then separated onto seasons (Fig. 4d to f). Focusing on one season leads to greater biases due to under-sampling, as fewer profiles are cumulated. Nevertheless, differences remain very low whatever the season as for the total SR histogram, and most differences are detected whether for high levels or mid-levels in winter and spring. The greatest errors in terms of magnitude (for values passing the threshold of cloud detection $\operatorname{SR}(\mathrm{z})=$ 5) are detected in fall and summer consistently with Fig.3 but the differences appear on more levels in spring and winter (than fall and summer) in cloud fraction profiles (Fig. 3). Consequently, the biases of sampling detected in cloud fraction profiles (sect. 3.1) correspond mostly to SR values between 5 and 20. Also, for high clouds (above $8 \mathrm{~km}$ ) the errors are maximal in fall in Fig.4 while it was summer in Fig 3: this is linked to the definition of the cloud fraction (cf. sect. 2.1.) explaining that the cloud fraction depends on cloudy profiles but also on fully attenuated profiles. Between 8 and 10km, there are more differences of fully attenuated profiles in fall than in summer (signal drowned in the grey shade): this explains why the errors of cloud fraction are bigger in summer even though SR shows more differences of cloudy profiles in fall. The overestimate and underestimate of SR values due to CALIPSO under-sampling depend on the levels. Around 9-10 km, where the maximum of clouds is detected, the satellite under-sampling always leads to an overestimate of SR values (as the cloud fraction in Fig3).

Only simulation is used in this section, despite the fact it very likely contains biases in the representation of clouds. The estimation of these biases is the purpose of the next section, and in particular concerning the seasonal cycle of clouds. Further computations of sampling errors that would have been estimated by observations are presented in table 3 and discussed in the conclusion. 


\section{CHARACTERIZATION OF THE SEASONAL CYCLE AND}

\section{ABILITY OF THE MODEL TO REPRODUCE IT}

For meso-scale models, cloud biases have been detected in previous studies, but only for some case studies (Chiriaco et al. 2006; Chepfer et al. 2007; Chaboureau et al. 2002). The aim of this section is to provide an evaluation of clouds over the entire Euro-Mediterranean region and throughout several years of observations. Hence, both the mean annual and seasonal biases of the vertical distribution of clouds and the difference of amplitude of the seasonal cycle will be assessed. The average annual cycle is studied using observations and the simulation over the period June 2006 to December 2011. Only the simulation along the satellite tracks is used here in order to be consistent with observations. The seasonal variability of cloud fraction profiles is studied separately over continental Europe and over the Mediterranean Sea. Using land/sea mask, continent stands for the grid-boxes over continental Europe in the blue rectangle in Fig.1a while sea stands for the grid-boxes located over the Mediterranean Sea in the red rectangle of the same figure. Note that we also studied the variability over the Atlantic Ocean and as the results were very similar to the continent they are not shown in this paper.

\subsection{CLOUD FRACTION PROFILES}

\subsubsection{SEASONAL CYCLE}

In this sub-section, only observations are examined to describe the seasonal cycle of vertical distribution of clouds. Pink solid lines in Fig. 5a shows $\mathrm{CF}_{\mathrm{GOCCP}}(\mathrm{z})$ averaged over the continent from 2006/06 to 2011/12. Figure $5 \mathrm{~b}$ is same as Fig. $5 \mathrm{a}$ but averaged over the sea. Notice that in our case, continent is located between $40^{\circ} \mathrm{N}$ and $52^{\circ} \mathrm{N}$ while the Mediterranean Sea is between $30^{\circ}$ and $42^{\circ}$. The Mediterranean Sea is under the influence of both mid latitude synoptic disturbances that affects the European climate (in particular winter; Cassou et al. 2004, Yiou et al. 2007) and the subtropical storms (Rysman et al. 2013). The average profile from observations shows that: 
- $\quad$ at a given level, the cloud fraction is greater over the continent than over the sea (Fig. 5a and b). This might be explained by the fact that frontal (ascending large scale motions) clouds and stratocumulus clouds (light subsiding motions and near surface instability) are more frequent over Europe (land) than over Mediterranean Sea (Cheruy and Aires 2009).

- $\quad$ over the continent, low clouds occurrence is equivalent to high clouds occurrence, while over the sea high clouds are a little more frequent than low clouds (Fig. 5b). This might be linked to a lack of stratocumulus and stratus clouds over the Mediterranean (Cheruy and Aires 2009).

In Fig. 5a and b, the pink shades represent the range of seasonal variability, when computing a profile by season, averaged from 2006 to 2011. The purpose of this representation is to estimate the envelope of variability of the vertical profile during a complete annual cycle (in observations), and evaluate its representation in the simulation (Sect. 4.2). The amplitude of the observed seasonal variability shows that the variability of high clouds is equivalent to the variability of low clouds, over the continent as well as over the sea. This seasonal amplitude is estimated to $5 \%$ in terms of cloud fraction for high and low levels.

In Fig. 5c and d, the shades are envelopes containing 4 profiles of relative anomaly of each season comparing to the profile averaged over the 4 seasons and 6 years. It shows that over the continent, the observed relative variability ranges between $-40 \%$ and $50 \%$ of the mean annual cloud fraction profiles (Fig. $5 \mathrm{c}$ ). This relative anomaly has equivalent amplitude for the different vertical levels. Over the sea the amplitude of seasonal variability is greater for low levels (more or less $100 \%$ ) than for mid and high levels (more or less 60\%) (Fig. $5 d)$.

To go further in details, the four seasons averaged over 2006 to 2011 are plotted separately in Fig. 5e (continent) and Fig. $5 \mathrm{f}$ (sea) for $\mathrm{CF}_{\mathrm{GOCCP}}(\mathrm{z})$ showing that for both continent and sea, the high clouds in summer and fall (red and light blue lines) are less frequent (especially summer $\mathrm{CF}_{\mathrm{GOCCP}}(\mathrm{z})$ around $5 \%$ ) and occur at higher altitude $(\approx 10 \mathrm{~km})$ than high clouds in winter and spring $\left(\approx 8 \mathrm{~km}\right.$ with $\mathrm{CF}_{\mathrm{GOCCP}}(\mathrm{z})$ around $\left.9 \%\right)$. This result is expected because of the altitude of the tropopause that is minimal at the end of winter and maximal at the end of summer (Appenzeller et al. 1996) and it affects clouds top height (Gettelman and Forster 2002). The figures also show that the cloud fraction is weak in the mid-levels for the 4 seasons in both continent and sea and particularly in summer over the sea. The low clouds are frequent in winter over both continent and sea. Summer and fall profiles show a second maximum at low levels, even if less pronounced than winter, while spring profiles show more homogeneity from ground up to 6-7 km. 
The great relative variability of $\mathrm{CF}_{\mathrm{GOCCP}}(\mathrm{z})$ over the sea shown in Fig $5 \mathrm{~d}$ around $2-3 \mathrm{~km}$ is explained by the small values of $\mathrm{CF}_{\mathrm{GOCCP}}(\mathrm{z})$ in summer while they are large in winter (Fig. 5f). Note that winter clouds are under the large scale influence while summer clouds are under mesoscale influence (air-sea fluxes, topography) (Chaboureau and Claud 2006).

\subsubsection{SIMULATED SEASONAL CYCLE}

The seasonal vertical cloud structure has been characterized with CALIPSO observations. The goal of this subsection is to evaluate this structure in the simulation and focus on the similarities and the differences with the observed seasonal variability.

As for observations, the average simulated cloud fraction profile is maximal around 9km (blue line in Fig 5a and b). Nevertheless, in average, the simulation over-estimates high cloud fraction (above $6 \mathrm{~km}$ ), for both continent $\left(\mathrm{CF}_{\mathrm{WRF}+\text { sim }}(\mathrm{z}=9 \mathrm{~km})=30 \%\right.$ while $\left.\mathrm{CF}_{\mathrm{GOCCP}}(\mathrm{z}=9 \mathrm{~km})=10 \%\right)$ and sea $\left(\mathrm{CF}_{\mathrm{WRF}+\text { sim }}(\mathrm{z}=9 \mathrm{~km})=20 \%\right.$ while $\left.\mathrm{CF}_{\mathrm{GOCCP}}(\mathrm{z}=9 \mathrm{~km})=7 \%\right)$; the difference of the magnitude of the maximum of high clouds between observations and the simulation is larger over the continent than over the sea.

Under $6 \mathrm{~km}$, the cloud fraction is under-estimated in the simulation over both areas. The fact that WRF overestimates the high clouds probably enhances the underestimate of low and mid clouds due to the exacerbated attenuation of simulated lidar profiles. Nevertheless, another study based on comparisons of the same simulation but with ground-based lidar located near Paris (France) shows that the model actually under-estimates the amount of low clouds, in particular in summer (Bastin et al., under review). Figures in Annex 2 also confirm that this underestimate of low clouds is not only due to lidar attenuation: the map of low clouds directly computed from the total condensed water in the simulation (hence without the lidar simulator) shows that they are almost absent in summer (less than 10\%). The wrong vertical distribution of cloud layers has already been noticed with a mesoscale model for some case studies (Chaboureau et al. 2012) and the under-estimation of low clouds in summer is also a known result for GCMs in general over mid-latitudes (Cheruy et al. 2013).

Despite this bias, the range of seasonal variability of $\mathrm{CF}_{\mathrm{WRF}+\mathrm{sim}}(\mathrm{z})$ (blue shade) is by the same order of magnitude than the range of seasonal variability of $\mathrm{CF}_{\mathrm{GOCCP}}(\mathrm{z})$ over the continent (Fig. 5a), but is larger over the sea for the 
high clouds and narrower for mid and low clouds (Fig. 5b). It is confirmed by the relative seasonal variability profiles (blue shades in Fig. $5 \mathrm{c}$ and d), showing that:

- $\quad$ Above $9 \mathrm{~km}$, the simulation and the observations have equivalent amplitude of relative variability (more or less $\sim 50 \%$ ): even if the result is true over both continent and sea, the simulated variability at this altitude is closer to the observed variability over the sea.

- For mid and low clouds, the simulated amplitude of the relative variability over continent is twice greater than the observed amplitude (more or less $100 \%$ against $50 \%$ ). Over the sea, the simulated relative variability is greater than observed but the magnitude is by the same order.

Both observations and simulation agree that:

- The relative range of variability of mid and low clouds is greater than the relative range of variability of high clouds: In the simulation, this could be due whether to real seasonal variability of clouds in the model or a bias due to the very weak amount of clouds at low and mid levels. Actually, a great relative anomaly could be due to a great absolute anomaly but also to a weak cloud fraction.

- Mid and low levels variability is greater over the sea than over the continent, especially due to summer differences.

Analyzing separately the four seasons (Fig. $5 \mathrm{~g}$ and h) shows that despite the overestimate of high clouds and the underestimate of low clouds, some characteristics of the observed profiles are well simulated by the model over both areas: (i) a maximum at $10 \mathrm{~km}$ for summer and fall and at $8 \mathrm{~km}$ for winter and spring; (ii) less mid clouds than high clouds over both areas (Fig. 5 e and $\mathrm{f}$ ), with an almost zero $\mathrm{CF}_{\mathrm{WRF}+\text { sim }}(\mathrm{z})$ at these levels (except for winter where it's around $2.5 \%$ ); iii) a second maximum at low levels except in spring. This maximum is less pronounced in simulation than observations but exists except over the sea in summer: Fig. $11 \mathrm{~d}$ and e (Annex 2) show that in summer no mid or low clouds are represented over the sea. This figure also gives an idea of the spatial variability of occurrence of cloud layers from the simulation, even if not evaluated against observations.

\subsection{HISTOGRAMS OF SCATTERING RATIO}

Section 4.1. showed that the simulation over-estimates the occurrence of high clouds and under-estimates occurrence of low clouds, in particular in summer, but reproduces consistently the seasonality of clouds occurrence at each level and the amplitude of relative seasonal variability over the sea (Fig. 5d). It is now 
necessary to understand which clouds, in term of physical properties, are simulated for each season, in particular because the occurrence of clouds is not enough to evaluate the properties of clouds that can also present a significant variability. Since SR values are linked to the optical depth and optical properties of the cloud particle (type of particle, size, and concentration) (Chepfer et al. 2013), histograms of SR(z) are computed (Fig. 6) following the same method as in Fig. 4a-b, by cumulating SR profiles from 2006 to 2011 in each season (each line in the figure).

We first focus on $\operatorname{SR}(\mathrm{z})$ values greater than 5, passing the threshold of cloud detection. Both simulation and observations agree that the SR occurrence is dominant between 6 and $12 \mathrm{~km}$ and for $5<\mathrm{SR}(\mathrm{z})<20$ at all seasons. The overestimate of simulated high clouds (Sect. 4.1.2.) is mostly an overestimate of high clouds with low $\operatorname{SR}(z)$ values $(\operatorname{SR}(z)<20)$, and the occurrence of $5 \leq \operatorname{SR}_{W R F+\operatorname{sim}}(z)<20$ is around $7 \%$ when occurrence of $\mathrm{SR}_{\mathrm{GOCCP}}(\mathrm{z})$ is around $2 \%$. In the observations, low clouds are dominated by strong $\mathrm{SR}(\mathrm{z})(>60)$, a cloud category which is entirely missed by the simulation, whatever the season. Those clouds probably correspond to stratus clouds that appear mostly over Atlantic Ocean and continental Europe and stratocumulus clouds that appear particularly over Atlantic ocean but also over Europe and Mediterranean (Cheruy and Aires, 2009). Stratus clouds are formed when moist air near ground level starts to condensate (Khvorostyanov, 1995) while stratocumulus clouds are driven by convection and associated most of the time to strong temperature inversion at the top of the boundary layer (Cheruy and Aires, 2009). For these low clouds, only clouds with $40 \leq \operatorname{SR}(\mathrm{z})<60$ are simulated. For mid-levels, the $\mathrm{SR}(\mathrm{z})>60$ are also missed by the simulation.

The first bar of each SR histogram $(\operatorname{SR}(z) \leq 0.01)$ represents the full attenuation of the lidar. The number of fully attenuated profiles is greater in the simulation and the attenuated profiles occur at higher levels than the observed ones, whatever the season. This is consistent with the overestimate of high clouds and suggests that even if it's not the main reason explaining the lack of low and mid clouds, the overestimate of fully attenuated profiles increases the low and mid clouds deficit in the simulation using the lidar simulator. Also note that SR values for high clouds in the simulation are less than 20: so, the attenuation is mostly induced by the vertical extent of clouds as the optical depths of each layer are additive: typically $\operatorname{SR}(z)=5$ corresponds to an optical depth of 0.07 for a cirrus of $1 \mathrm{~km}$ depth at $10 \mathrm{~km}$ (Chepfer et al. 2013). This means that for clouds of $5 \mathrm{~km}$ depth, the optical depth is around 0.35 .

This histogram representation also confirms that despite the differences between simulation and observations, the seasonality of $\operatorname{SR}(\mathrm{z})$ distribution is respected in the simulation: 
- In winter (Fig 6a and b): the simulation creates, in comparison to other seasons, a large amount of low thick clouds and some thinner clouds, even if they are underestimated. The large amount of high clouds with $\operatorname{SR}(z)<20$ is also simulated.

- $\quad$ Spring (Fig. 6c and d) and fall (Fig. 6g and h) histograms are very similar, with many high and optically thin clouds in both observations and simulations. The difference between spring and fall, spotted by observation as well as simulation, is that in spring there are more mid optically thin clouds.

- In summer, the minimum of mid clouds observed with GOCCP (Fig. 6e) in comparison with other seasons is also simulated.

To summarize, the simulation overestimates high clouds with low $\mathrm{SR}(\mathrm{z})$ values whatever the season over different layers (more than 6 layers with our vertical resolution) and this leads to a lot of attenuation of the simulated lidar signal. Low clouds as detected by a lidar are underestimated in the simulation, in particular the low very thick clouds that are present in the observations: it is both a consequence of the over-estimation of the fully attenuated profiles and a real underestimate of low clouds as it was explained in Sect. 4.1. However, the seasonality of $\operatorname{SR}(z)$ histograms is well captured by the model.

As expected, the simulated clouds' vertical structure showed high differences with the vertical structure observed by CALIPSO. This highlights the importance of the vertical structure: the overestimate of high clouds would compensate with the underestimate of low clouds when computing cloud cover and the model biases would have been smaller (computing the vertically averaged cloud fraction: simulation 5\%, observations $3.7 \%$ over the sea and $8 \%$ versus $5.6 \%$ over the continent). A new important result is the ability of the model to simulate the amplitude of the seasonal variability of the cloud distribution (vertical distribution and SR(z) values distribution). This allows us to use these datasets (simulation and observations) to address the issue of the inter-annual variability of cloud vertical profile.

\section{INTER-ANNUAL VARIABILITY}

\subsection{AMPLITUDE OF INTER-ANNUAL VARIABILITY}

The goal of this section is to study the inter-annual variability of the vertical cloud structure over Europe with observations and evaluate the simulation's ability to reproduce it over the 6 common years. Shades in Fig. 7a 
(continent) and b (sea) show the standard deviation (STD) of the 2006 to 2011 winter cloud fraction profiles for both simulation and observations. Figures $7 \mathrm{c}$ and $\mathrm{d}$ are the same but for summer. This STD calculation is an estimation of the inter-annual variability in a given season. The altitude where the observed variability (pink shade) is maximal or minimal is well reproduced by the simulation (blue shade), for winter over both continent and sea and for summer over the sea.

In winter, the range of inter-annual variability of the observed cloud fraction is greater for high levels than for mid and low levels (Fig. 7.a and b). The smaller variability of low clouds over the sea and the continent is not related to a smaller occurrence of clouds since Fig. 5e and $\mathrm{f}$ indicate that the cloud fraction of high clouds is equivalent to the cloud fraction of low clouds for both continent and sea, in the observations. The simulation well reproduces the behavior of the observed inter-annual variability with greater amplitude for the high levels.

In summer (Fig7 $\mathrm{c}$ and d), the amplitude of the observed inter-annual variability shows a different behavior from winter. Over the continent, mid-level cloud occurrence is variable from one year to another, such as for low clouds. High clouds occurrence is more stable from one year to another. Over the sea, the high cloud occurrence is a little bit more variable than the mid and low ones. Simulation does not well reproduce this variability: the variability is large at high levels only for both areas. The weak variability of simulated low clouds is probably due to the small cloud fraction simulated in summer (Fig. $5 \mathrm{~g}$ and $\mathrm{h}$, red profiles).

Anyway, the simulation always over-estimates the range of inter annual variability for high clouds, whatever the season and the area (Fig. 7a to d). This over-estimation is enhanced when considering the total envelope of variability of clouds (maximums and minimums for each layer) traducing the behavior of extreme values (solid lines in Fig. 7e, f, $g$ and $\mathrm{h}$ ) instead of the mean one (shades in Fig. 7). For high clouds, the inter-annual variability is very large in the simulation, and the extreme events in terms of cloudiness are intense in winter and in summer over the continent. The relative range of the total variability of high clouds is around 25 to $50 \%$ greater than the STD in the simulation (comparing the solid blue line with the blue shade) versus 30 to $60 \%$ greater for observations (comparing the solid pink line with the pink shade) over both continent and sea for winter and summer.

Extremes are less intense at low and mid-levels, in particular in summer for the simulation where there are almost no clouds. 
To compare this variability with the uncertainty linked to the satellite sampling, $\mathrm{CF}_{\mathrm{WRF}+\operatorname{sim}^{\mathrm{T}}}$ (z) (i.e. with the complete simulation sampling) STD is also plotted in black line in Fig. 7a and b. The inter-annual variability of the $\mathrm{CF}_{\mathrm{WRF}+\text { sim }^{\mathrm{T}}}^{\mathrm{T}}(\mathrm{z})$ has the same behavior than the inter-annual variability of $\mathrm{CF}_{\mathrm{WRF}+\text { sim }}(\mathrm{z})$ with some differences that depend on the levels, the season and the area. In winter, the relative errors of estimation of the amplitude of inter-annual variability of high clouds are around $15 \%$ over the continent and $20 \%$ over the sea where it's more dependent on the altitude; the maximum of error is reached at $8 \mathrm{~km}(50 \%)$. In summer, the variability is strongly modulated by local events (storms and mesoscale convective systems). These events, occurring typically at spatial scales ranging between $10 \mathrm{~km}$ to $100 \mathrm{~km}$ during less than 3 hours (Rysman et al. 2013), are more easily missed by CALIPSO considering its undersampling. It generates significant differences of variability between the two samplings (Fig. 7c and d), the total one being less variable than the CALIPSO one. It is then more questionable to study the inter-annual variability of clouds in summer from observations at this spatial resolution of $20 \times 20 \mathrm{~km}^{2}$.

\subsection{CLOUDS NATURAL VARIABILITY IN WINTER}

The purpose of this section is to analyze the 8 years of observations and 23 years of simulation taking into account the model biases evaluated previously to try to estimate the natural variability of clouds and how much these respective datasets can be used i) to detect extremes and ii) as a referent period to detect possible trends. The simulation's full resolution (one profile per night extracted at 00UTC for each grid-box) is used. Only winter is considered: actually Sect.5.1 showed that the inter-annual variability is better simulated in winter than in summer, and is less affected by the satellite sampling.

Figure 8a shows the $\mathrm{CF}_{\mathrm{WRF}+\text { sim }}{ }^{\mathrm{T}}$ anomaly simulated profiles averaged over the Mediterranean Sea for every winter from 1990 (December 1989, January and February 1990) to 2011 (December 2010, January and February 2011) compared to winter mean 2007-2011 (blue profile in Fig. 5h; this period is used as it is the common period for observations and simulations, which is important when computing anomalies). Figure $8 b$ is the same as Fig. 8a for observations for each winter with available observations from 2007 to 2013 . The anomaly is compared to winter mean 2007-2011 (pink profile in Fig. 5f). Fig. 8c and d are the same as Fig. 8a and b over the continent.

Despite the model biases leading to an overestimate of high clouds and an underestimate of mid and low clouds and despite the biases due to satellite under-sampling in winter (cf. 5.1), the sign of observed anomalies are most of the time reproduced by the simulation during the 5 years and at the right altitudes: the 2008 strong negative 
anomaly of high clouds over both sea and continent, the 2011 positive anomaly of high clouds over the sea and mid clouds over the continent and also the 2010 strong positive anomaly signal of high clouds over both continent and sea that are detected with CALIPSO are also simulated by the model. Some observed anomalies are poorly simulated by the model, particularly over the continent. The obvious ones are: the positive anomaly of 2007 observed at $8 \mathrm{~km}$ (Fig. 8.d) that is negative with the simulation (Fig. 8.c) and the almost null observed anomaly of 2009 around $8 \mathrm{~km}$ is simulated as a strong positive anomaly. Also, the variability of the maximum altitude of the anomalies are most of the time well reproduced by the model (e.g. in 2010 over the continent, altitude $\max =10 \mathrm{~km}, 2009$ low clouds altitude $\max =2 \mathrm{~km}$ ) and sometimes not (altitude max of high clouds anomaly over the sea in $2007=12 \mathrm{~km}$ for observations and $9 \mathrm{~km}$ in the simulation). Some other particular anomalies are noticed over the 22 years: e.g. the $1996^{\text {th }}$ high clouds signal but at a different altitude than in 2010 over the sea, the 1991-1993 enhanced low clouds signal also over the sea, the 1994 high clouds signal over the continent.

Some high cloud strong anomalies only appear over the continent (high clouds positive anomaly in 1994) or over the sea (negative anomaly of low clouds in 2007) while others appear over both areas (2010 high clouds anomaly). This highlights the importance of the spatial distribution of clouds that is not very discussed in this paper because it cannot be seriously evaluated. However, the separation between sea and continent is useful.

Winter 2010 shows a strong anomaly of high clouds occurrence, even when compared to the 22-year-time series (Fig. 8a and c). The horizontal map of high cloud fraction of winter 2010 anomaly relative to the cloud fraction averaged over the 22 winters of the simulation is shown in Fig. 12 (annex 3). As discussed by Cattiaux et al. (2010), winter 2010 is associated with a particularly cold season resulting from the persistence of the negative phase of the North Atlantic Oscillation ( $\mathrm{NAO}^{-}$). During the negative phase of the NAO, storms bring moist air from the Atlantic into the Mediterranean Sea and dry and cold air over northern Europe (Trigo et al. 2002) and cloud systems are frequent over the western part of the Mediterranean Basin (Chaboureau and Claud 2006): the signature of high clouds storm track over southern Europe and the Mediterranean Basin (CF anomaly around 5\%) is noticeable in Fig. 12 (annex 3), as well as the advection of dry and cold air favoring clear sky (and hence negative anomaly of clouds) over Northern Europe (Trigo et al. 2002). However, winter 2010 shows an even stronger cloud fraction anomaly over the eastern part of the domain where it reaches $9 \%$. Deeper analysis of this winter in terms of interactions between clouds and dynamics is then needed but beyond the scope of this study. 
ERA-Interim reanalysis, which forces the simulation, contains the large-scale conditions which drive cloud anomalies: it is then rational that the simulation is able to reproduce these specific anomalies. It gives us confidence to use the complete time-period of this simulation to quantify the amplitude of cloud variability over two decades. It should allow determining how many years are needed to cover the effect of internal climate variability on cloud vertical profile, at present and without any external forcing.

In Fig. 9a, the mean value of CF at $9.5 \mathrm{~km}$ (altitude where CF is maximal in 2010) is extracted each year over the Mediterranean Sea. It gives 22 values of $\mathrm{CF}_{9.5}$. The blue bars represent the standard deviation (STD) of these $\mathrm{CF}_{9.5}$ (y-axis) estimated by varying the number of years (x-axis): the first blue bar is the $\mathrm{CF}_{9.5} \mathrm{STD}$ over 5 years (from 2007 to 2011), the second over 6 years (2006 to 2011 for the simulation (blue axis)), and so on. Pink bars and pink axis are the same but for observations. Fig. 9b is the same as Fig. 9a but over the continent.

When considering the same years for observations and simulation, the simulated inter-annual variability at this altitude is greater than the observed one for both continent and sea. This is consistent with results in Sect. 5.1. (Fig. $7 \mathrm{~b}$ and $7 \mathrm{f}$ for high clouds). The interannual variability of cloud fraction at $9.5 \mathrm{~km}$ is greater over the continent $(\approx 4.5 \%)$ than over the sea $(\approx 3.8 \%)$. Also, the variability is more dependent on the years considered over the continent than over the sea: $\mathrm{STD}$ of $\mathrm{CF}_{9.5}$ ranges from $3.4 \%$ to $4 \%$ over the sea and from $4.1 \%$ to $4.9 \%$ over the continent. We notice that over the continent the STD computed over 13 and more years is around $4.1 \%$ : it varies of $0.1 \%$ between 13 and 22 years, while it varies of $0.7 \%$ between 5 and 22 years. The STD of $\mathrm{CF}_{9.5}$ is less dependent on the number of years when computed over 13 and more years. Over the sea this statement is not valid: the variability of STD of $\mathrm{CF}_{9.5}$ stabilizes between $13-20$ years $(0.2 \%$ compared to $0.6 \%)$ but decreases significantly between 21 and 22 years (making the STD variability between 13 and 22 years around $0.5 \%$ ).

The blue dots are the winter $2010 \mathrm{CF}_{9.5}$ anomaly computed relative to the mean $\mathrm{CF}_{9.5}$ averaged over different time periods as indicated by the blue axis, for the simulation. The pink dots are the same as the blue dots for observations. This winter 2010 specific anomaly is confirmed in Fig. 9, where both observations and simulation agree that 2010 is a particular winter, identifying a particular event in terms of cloud occurrence since the anomaly is greater than the corresponding STD. For observations, over both sea and continent, the $\mathrm{CF}_{9.5}$ anomaly in winter 2010 is greater than 1.5 STD. It's up to twice STD for the simulation over the sea, in particular for time periods more than 10 years. The $2010 \mathrm{CF}$ anomaly is less marked over the continent than over the sea with the simulation (Fig. 9b). 
This takes us back to the question of spatial distribution that is not very discussed in this paper and that is necessary to understand some processes. Why the anomaly is more marked over the sea? Which feedbacks does this imply? Also, it appears that even if the simulation captures the anomaly, its intensity against the natural variability keeps uncertain despite we consider a winter nighttime situation where most of variability is driven by large scale. As discussed by Hawkins and Sutton (2009), internal variability and model uncertainties are strong. However, this study paves the way for a better assessment of clouds trends.

\section{CONCLUSION}

The goal of this study was to characterize the nighttime cloud vertical profile variability over Europe. Actually, analyzing the behavior of the seasonal and inter-annual vertical structure of clouds over the Euro-Mediterranean region is necessary to understand some climate anomalies that are not entirely explained by large scale dynamics.

We used CALIPSO-GOCCP observations and one WRF/MedCordex simulation that is nudged towards the reanalysis ERA-interim to reduce the biases due to dynamical effects. As the CALIPSO footprint has a small swath (the lidar essentially documents a curtain), it under-samples the area, which can impact the study. Hence, we first estimated the bias on the cloud fraction profile due to CALIPSO under-sampling in comparing simulated cloud profiles under the satellite flight track with simulated cloud profiles over the entire area. This comparison shows that biases on cloud fraction profiles due to CALIPSO under-sampling mainly depend on: i) clouds occurrence, ii) clouds spatial distribution and iii) clouds temporal variability. In particular, the bias can be nonnegligible during fall and summer seasons, when convective clouds are more frequent than during the rest of the year. Nevertheless, the detailed lidar height-intensity histograms $(\operatorname{SR}(z))$ show that the effect of under-sampling mostly occurs in the non-cloudy bins. However, this assessment is based on simulation, which does not properly simulate cloud properties. As a consequence, in reality, the actual bias due to under-sampling might be different of the one estimated here. Combining the sampling errors estimated by the simulation and the model biases, an estimation of the actual sampling biases is presented in Table 3. The computation method is presented in Annex 4. Actual errors of sampling averaged over the seasons are shown to be smaller than $1 \%$ in average in terms of 
cloud fraction while the relative errors estimated are $12 \%$ for low clouds, $25 \%$ for mid clouds and $7 \%$ for high clouds. These values are comparable to the ones estimated by the model. These values can be larger for some levels (16\% for high clouds, $19 \%$ for low clouds and up to $35 \%$ for mid clouds).

Then we addressed the three following questions in the current paper: (1) What is the seasonal variability of the cloud vertical distribution over Euro-Mediterranean area? (2) What is its inter-annual variability? (3) Are simulations able to reproduce the amplitude of these variabilities?

1) The seasonal variability of the cloud vertical distribution over Euro-Mediterranean area has been documented using 8 years of CALIPSO observations during nighttime. It results that clouds are more frequent (around $2 \%$ more clouds) over the continent than over the sea. This is probably linked to the geographical position of the Mediterranean as a transition region between Northern fluxes that are wet and cool and African fluxes that are dry and hot (Mariotti et al. 2015). Cheruy and Aires (2009) show that $70 \%$ of clouds population over the EuroMediterranean area is whether frontal (ascending large scale motions), stratocumulus or shallow cumulus (subsiding motions and near-surface instability) clouds. They also show that frontal and stratocumulus clouds are frequent over land while shallow cumulus clouds are frequent over both land and sea. Also, complex topography over land, particularly mountains, are favorable to the formation of cloud systems.

But the clouds are less variable from one season to another over the continent (less than $50 \%$ relative variability) than over the sea (relative variability reaches $100 \%$ in low levels). Besides, high clouds occurrence is shown (with observations) to be equivalent to low clouds occurrence in summer and winter while mid clouds are around $5 \%$ smaller in terms of cloud fraction.

2) The cloud inter-annual variability is linked to the large scale circulation generating intra-seasonal variability and spatial distribution that are not discussed in this paper. Nevertheless, the eight years of CALIPSO observations show that winter inter-annual variability is around $4 \%$ for high clouds and $1 \%$ for low and mid clouds. Boé and Terray (2014) showed that cloud cover in 2031-2050 is expected to decrease by $3 \%$ over southern Europe and Mediterranean Sea when compared to 1961-1990. This decrease is within the range of the inter-annual variability of observed cloud fraction and weaker than the one simulated by this model and might not be totally associated to climate change. 
3) Then we evaluated clouds vertical distribution in the WRF/MedCordex simulation. Comparisons between the observations and the "model+lidar simulator" outputs showed that the model overestimates the high clouds (20\% more cloud fraction) and underestimates the mid and low clouds (5\% less cloud fraction). This seems to be a persistent feature in models over Europe, which does not depend on spatial and temporal resolution of the model nor the model type (e.g Chiriaco et al. 2006 and Chaboureau et al. 2002 for mesoscale models; Cheruy et al. 2013 for GCMs, Cesana and Chepfer 2012, Nam et al. , 2012; Tsushima et al. 2013). This default was pointed out using case studies observations (ground base sites and field campaigns) in the previous studies, and it is confirmed here using eight years of satellite observations by active sensors. As mentioned by Hawkins and Sutton (2009), there is room to reduce model uncertainty, in particular by improving physical parameterizations leading to this wrong vertical distribution of cloud layers. Despite these biases, the model is able to simulate realistic seasonal cycle.

Regarding the inter-annual variability in winter, the model simulates realistic inter-annual variability of spatially averaged CF in winter that is overestimated for high clouds (up to twice larger than observations for high clouds). The range of variability of $\mathrm{CF}$ in the simulation varies sometimes at different altitudes and with different intensity from the observations, particularly in summer. This is part of the model uncertainty that might be more complicated to reduce as it is also associated to clouds feedback. 


\section{REFERENCES}

Appenzeller, C., J. R. Holton, and K. H. Rosenlof (1996): Seasonal variation of mass transport across the tropopause. Journal of Geophysical Research, Atmospheres, 101(D10), 15071-15078, doi:10.1029/96JD00821.

Bastin S., Chiriaco M., and Drobinski P. (2015): Control of radiation and evaporation on temperature variability in a WRF regional climate simulation: comparison with colocated long-term ground based observations near Paris. In revision to Clim. Dyn.

Boé J. and Terray L. (2014): Land-sea contrast, soil-atmosphere and cloud-temperature interactions: interplays and roles in future summer European climate change. Climate Dynamics. 42:683-699 DOI $10.1007 / \mathrm{s} 00382-013-1868-8$

Cassou C., L. Terray, J. W. Hurrell, and C. Deser (2004): North Atlantic Winter Climate Regimes: Spatial Asymmetry, Stationarity with Time, and Oceanic Forcing. J. Climate, 17, 1055-1068. doi: http://dx.doi.org/10.1175/1520-0442(2004)017<1055:NAWCRS>2.0.CO;2

Cassou C., Laurent Terray, and Adam S. Phillips (2005): Tropical Atlantic Influence on European Heat Waves. Journal of Climate, 18, 2805-2811. doi: http://dx.doi.org/10.1175/JCLI3506.1

Cattiaux J., R. Vautard, C. Cassou, P. Yiou, V. Masson-Delmotte and F. Codron (2010): Winter 2010 in Europe: A cold extreme in a warming climate. Geophysical Research Letters, 37,20, DOI: $10.1029 / 2010 G L 044613$

Cesana G. and H. Chepfer (2012): How well do climate models simulate cloud vertical structure? A comparison between CALIPSO-GOCCP satellite observations and CMIP5 models. Geophysical Research Letters, 39, L15704, doi: 10.1029/2012GL053153

Chaboureau J.P., J.P. Cammas, P. J. Mascart, J.P. Lafore, and J.P. Pinty (2002): Mesoscale model cloud scheme assessment using satellite observations. Journal of Geophysical Research, 107, no. D16, 4301, $10.1029 / 2001 \mathrm{jd} 000714$

Chaboureau J. P. and C. Claud (2006): Satellite-based climatology of Mediterranean cloud systems and their association with large-scale circulation. J. Of Geophys. Res., 111, D01102, doi:10.1029/2005JD006460. 
Chepfer, M. Chiriaco, and V. Wulfmeyer (2012): Long-range transport of Saharan dust and its radiative impact on precipitation forecast: a case study during the Convective and Orographically induced Precipitation Study (COPS). R. Met. S, 137, 236-251. DOI: 10.1002/qj.719

Chepfer H., M. Chiriaco, R. Vautard, and J. Spinhirne (2007): Evaluation of MM5 Optically Thin Clouds over Europe in Fall Using ICESat Lidar Spaceborne Observations. Monthly Weather Review, 135, 2737-2753. DOI: 10.1175/MWR3413.1

Chepfer H., S. Bony, D. M. Winker, M. Chiriaco, J.-L. Dufresne, and G. Seze (2008): Use of CALIPSO lidar observations to evaluate the cloudiness simulated by a climate model. Geophysical Research Letters, 35 , L20804, doi: 10.1029/2012GL053385.

Chepfer, H., S. Bony, D. Winker, G. Cesana, J. L. Dufresne, P. Minnis, C. J. Stubenrauch, and S. Zeng (2010): The GCM-Oriented CALIPSO Cloud Product (CALIPSO-GOCCP). Journal of Geophysical Research, Atmospheres, 115, D00H16, doi:10.1029/2009JD012251

Chepfer H., G. Cesana, D. Winker, B. Getzewich, M. Vaughan, And Z. Liu (2013): Comparison of Two Different Cloud Climatologies Derived from CALIOP-Attenuated Backscattered Measurements (Level 1): The CALIPSO-ST and the CALIPSO-GOCCP. Journal of Atmospheric and Oceanic Technology, 30, 725-744. DOI: http://dx.doi.org/10.1175/JTECH-D-12-00057.1

Chepfer H., V. Noel, D. Winker, and M. Chiriaco (2014): Where and when will we observe cloud changes due to climate warming? Geophysical Research Letters 41, 8387-8395, doi: 10.1002/2014GL061792.

Cheruy F. and Filipe Aires (2009): Cluster Analysis of Cloud Properties over the Southern European Mediterranean Area in Observations and a Model. Monthly Weather Review, 137, 3161-3176. doi: http://dx.doi.org/10.1175/2009MWR2882.1

Cheruy F., A. Campoy, J.-C. Dupont, A. Ducharne, F. Hourdin, M. Haeffelin, M. Chiriaco, A. Idelkadi (2013): Combined influence of atmospheric physics and soil hydrology on the simulated meteorology at the SIRTA atmospheric observatory. Climate Dynamics. 40, 2251-2269, doi : 101007/s00382-012-1469-y 

Protat (2006): The ability of MM5 to simulate ice clouds: systematic comparison between simulated and measured fluxes and lidar/radar profiles at the SIRTA atmospheric observatory. Monthly Weather Review, 134, 897-918

Chiriaco M., Bastin S., Yiou P., Haeffelin M.,Dupont Jean-Charles, Stefanon M. (2014): European heatwave in July 2006: Observations and modeling showing how local processes amplify conducive large-scale conditions, Geophysical Research Letters, 41, Issue 15, pages 5644-5652, DOI: 10.1002/2014GL060205

Dee D., Uppala S., Simmons A., Berrisford P., Poli P., Kobayashi S., Andrae U., Balmaseda M.,

Dudhia J., (1989): Numerical Study of Convection Observed during the Winter Monsoon Experiment Using a Mesoscale Two-Dimensional Model. Journal of Atmospheric Sciences, 46, 3077-3107. doi: http://dx.doi.org/10.1175/1520-0469(1989)046<3077:NSOCOD>2.0.CO;2

Flaounas E., Drobinski P., Vrac M, Bastin S., Lebeaupin-Brossier C, Stéfanon M., Borga M. and Calvet J. C. (2013): Precipitation and temperature space-time variability and extremes in the Mediterranean region: Evaluation of dynamical and statistical downscaling methods. Climate Dynamics. 40, 2687-2705. DOI: $10.1007 / \mathrm{s} 00382-012-1558-\mathrm{y}$

Flaounas E., S.a Raveh-Rubin, H. Wernli, P. Drobinski, and S. Bastin (2014): The dynamical structure of intense Mediterranean cyclones. Climate Dynamics, 44, 2411-2427. DOI: 10.1007/s00382-014-2330-2 9 

moderate and intense precipitating systems in the Mediterranean region. Monthly Weather Review, 137: 39333959.

Gettelman A. And P.M. De F. Forster (2002): A Climatology of the Tropical Tropopause Layer. Journal of the Meteorological Society of Japan, Vol. 80, No. 4B, pp. 911-924. Doi: http://doi.org/10.2151/jmsj.80.911

Giorgi F., C. Jones, and G. Asrar (2009): Addressing climate information needs at the regional level: the CORDEX framework, WMO Bull., 58 (3) (2009), pp. 175-183

Hawkins E. and R. Stutton (2009): The potential to narrow uncertainty in regional climate predictions. Bulletin of American Meteorological Society, 90, 1095-1107. doi: http://dx.doi.org/10.1175/2009BAMS2607.1

Hong, S.Y., J. Dudhia, and S.H. Chen (2004): A revised approach to ice microphysical processes for the bulk parameterization of clouds and precipitation, Monthly Weather Review, 132, 103-120.

Kain J.S. (2004): The Kain-Fritsch Convective Parameterization: An Update. J. Appl. Meteor., 43, 170-181. doi: http://dx.doi.org/10.1175/1520-0450(2004)043<0170:TKCPAU>2.0.CO;2

Khvorostyanov V. I., (1995): Mesoscale processes of cloud formation, cloud-radiation interaction, and their modelling with explicit cloud microphysics. Atmospheric Research, 39, issue 1-3, pp1-67. doi:10.1016/0169-8095(95)00012-G

Kjellström, E., G. Nikulin, U. Hansson, G. Strandberg, and A. Ullerstig (2011): $21^{\text {st }}$ century changes in the European climate: uncertainties derived from an ensemble of regional climate model simulations. Tellus A, Series A, 63A(1), 24-40, doi: 10.1111/j.1600-0870.2010.00475.x.

Lebeaupin-Brossier C., S. Bastin, K. Béranger, and P. Drobinski (2015): Regional mesoscale air-sea coupling impacts and extreme meteorological events role on the Mediterranean Sea water budget, Climate Dynamics, 44, 1029-1051, DOI 10.1007/s00382-014-2252-z

Lenderink G., A. van Ulden, B. van den Hurk and E. van Meijgaard (2007): Summertime inter-annual temperature variability in an ensemble of regional model simulations: analysis of the surface energy budget. Clim. Change. 81: 1,233-274. DOI 10.1007/s10584-006-9229-9 

Mediterranean region in the midst of decadal variability. Climate Dynamics, 44, Issue 5-6, pp 1437-1456. DOI $10.1007 / \mathrm{s} 00382-015-2487-3$

Mlawer J. E., Taubma J. S., Brown D. P., Iancono M. J., Clough A. S. (1997): Radiative transfer for inhomogeneous atmospheres: RRTM, a validated correlated-k model for the longwave, Journal of Geophysical Research, 102, Issue D14, 16663-16682, DOI: 10.1029/97JD00237

Monin, A. S., and Obukhov, A. (1954): Basic laws of turbulent mixing in the surface layer of the atmosphere. Contrib. Geophys. Inst. Acad. Sci. USSR, 151, 163-187.

Nam, C., S. Bony, J.-L. Dufresne, and H. Chepfer (2012): The 'too few, too bright' tropical low-cloud problem in CMIP5 models, Geophysical Research Letters., 39, L21801, doi:10.1029/2012GL053421.

Noh Y., W. G. Cheon and S. Y. Hong (2003): Improvement of the k-profile model for the planetary boundary layer based on large eddy simulation data. Boundary-layer meteorology, 107, 401-427

Omrani H, Drobinski P, and Dubos T. (2013): Optimal nudging strategies in regional climate modelling: investigation in a big-brother experiment over the European and Mediterranean regions. Climate Dynamics, 41: 2451-2470, doi:10.1007/s00382-012-1615-6.

Omrani, H., Drobinski, P., Jourdier, B., and Brossier, C.L. (2014): Investigation on the offshore wind energy potential over the north western Mediterranean Sea in a regional climate system model. IEEE, Renewable Energy Congress (IREC), 2014 5th International, DOI: 10.1109/IREC.2014.6826956

Reiter E. R. , (1975): Handbook for Forecasters in the Mediterranean: Weather Phenomena of the Mediterranean Basin, Part 1. General Description of the Meteorological Processes, Environmental Prediction Research FacilityNaval Postgraduate School, Monterey, CA (1975), p. 344 Tech. Pap. 5-75

Rojas M., L. Z. Li, M. Kanakidou, N. Hatzianastassiou, G. Seze, and H. Le Treut (2013): Winter weather regimes over the Mediterranean region: their role for the regional climate and projected changes in the twenty-first century, Climate Dynamics. DOI 10.1007/s00382-013-1823-8

Ruti P, Somot S, Dubois C, Calmanti S, Ahrens B, Alias A, Aznar R, Bartholy J, Bastin S, Branger K, Brauch J, Calvet J-C, Carillo A, Decharme B, Dell'Aquila A, Djurdjevic V, Drobinski P, Elizalde-Arellano A, 
Gaertner M, Galn P, Gallardo C, Giorgi F, Gualdi S, Harzallah A, Herrmann M, Jacob D, Khodayar S, Krichak S, Lebeaupin C, L'Heveder B, Li L, Liguro G, Lionello P, Onol B, Rajkovic B, Sannino G, and Sevault F (2015) : MED-CORDEX initiative for Mediterranean climate studies, Bulletin of the American Meteorological Society. doi: http://dx.doi.org/10.1175/BAMS-D-14-00176.1

Rysman J.-F., S. Verrier, Y. Lemaître, and E. Moreau, (2013): Space-time variability of the rainfall over the western Mediterranean region: A statistical analysis, Journal of Geophysical Research Atmospheres, 118, 8448-8459, doi:10.1002/jgrd.50656

Salameh T, Drobinski P, and T. Dubos (2010): The effect of indiscriminate nudging time on large and small scales in regional climate modelling: Application to the Mediterranean basin. Q. J. R. Meteorol. Soc. 136(646): 170-182, doi:10.1002/qj.518.

Skamarock W. C. and J. B. Klemp (2008): A time-split nonhydrostatic atmospheric model for weather research and forecasting applications. Journal of Computational Physics, 227:3465-3485, DOI: 10.1016/j.jcp.2007.01.037.

Smirnova T. G., Brown John M., and B. Stanley G. (1997): Performance of Different Soil Model Configurations in Simulating Ground Surface Temperature and Surface Fluxes. Monthly Weather Review, 125:1870-1884. doi: http://dx.doi.org/10.1175/1520-0493(1997)125<1870:PODSMC>2.0.CO;2

Smirnova, T. G., J. M. Brown, S. G. Benjamin, and D. Kim (2000), Parameterization of cold-season processes in the MAPS land-surface scheme, Journal of Geophysical Research, 105(D3):4077-4086, doi:10.1029/1999JD901047.

Soden B. J. and I. M. Held (2006): An Assessment of Climate Feedbacks in Coupled OceanAtmosphere Models. Journal of Climate, 19:3354-3360. doi: http://dx.doi.org/10.1175/JCLI3799.1

Stauffer DR and Seaman NL. (1990): Use of four-dimensional data assimilation in a limited-area mesoscale model. part i: Experiments with synoptic-scale data. Mon. Weather Rev. 118(6): 1250-1277, doi:10.1175/1520-0493(1990)118. 

temperature feedbacks at meso-scale during summer heat waves over Western Europe, Clim Dyn, 42:1309-1324, DOI 10.1007/s00382-013-1794-9

Stephens G. L. (2005): Cloud Feedbacks in the Climate System: A Critical Review. Journal of Climate,

Tang Q., Guoyong Leng, and Pavel Ya. Groisman (2012): European Hot Summers Associated with a

Trigo R. M., T. J. Osborn, and J. M. Corte-Real (2002): The North Atlantic Oscillation influence on

Europe: climate impacts and associated physical mechanisms. Climate Research, 20: 917. doi:10.3354/cr020009 the seasonal variations in climate model cloud regimes. Climate Dynamics, V 41, Issue 9, pp 2679-2696. DOI:

Vaittinada Ayar P., Vrac M., Bastin S., Carreau J., and Gallardo C. (2015): Intercomparison of statistical and dynamical downscaling models under the EURO- and MED-CORDEX initiative framework: Present climate evaluations. Climate dynamics, doi:10.1007/s00382-015-2647-5

successors. Monthly Weather Review, 118, 2056-2081. doi: http://dx.doi.org/10.1175/15200493(1990)118<2056:MWROTN>2.0.CO;2

Winker D. M., Jacques R. Pelon, and M. Patrick McCormick (2003): The CALIPSO mission: spaceborne lidar for observation of aerosols and clouds, Proc. SPIE 4893, Lidar Remote Sensing for Industry and Environment Monitoring III, 1 (March 24, 2003). doi: http://dx.doi.org/10.1117/12.466539 
861 precipitation variability: influence of large-scale dynamics and trends. Climate Dynamics. 23: 63-78, DOI $862 \quad 10.1007 / \mathrm{s} 00382-004-0422-0$

Yiou, P., R. Vautard, P. Naveau, and C. Cassou (2007): Inconsistency between atmospheric dynamics and temperatures during the exceptional 2006/2007 fall/winter and recent warming in Europe, Geophysical Research Letters, 34, L21808, doi:10.1029/2007GL031981. 


\section{TABLE CAPTION}

867

868

869

Table 1: Definition of the datasets used for the study. Columns define the sampling method. Lines stand for the product used. SR is the scattering ratio measured by the lidar (annex 1) and CF is the percentage of clouds per gridbox.

Table 2: Maximal differences (i.e. absolute - “abs." - errors) between simulated cloud fractions extracted with full resolution and simulated cloud fraction extracted with CALIPSO sampling $\left[\mathrm{CF}_{\mathrm{WRF}+\operatorname{sim}}(\mathrm{z})-\mathrm{CF}_{\mathrm{WRF}+\operatorname{sim}}{ }^{\mathrm{T}}(\mathrm{z})\right]$

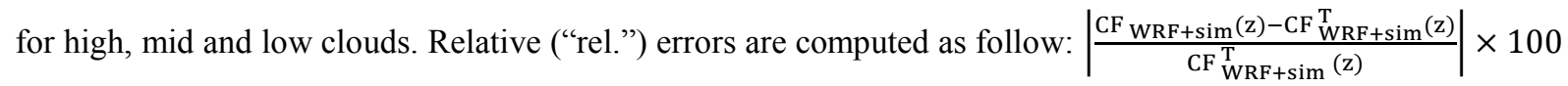
and represent the average value of the layer (low, mid, or high). $\mathrm{CF}_{\mathrm{WRF}+\text { sim }}(\mathrm{z})$ and $\mathrm{CF}_{\mathrm{WRF}+\text { sim }}{ }^{\mathrm{T}}(\mathrm{z})$ are averaged over 2006-2011 by seasons (columns).

Table 3: Estimation of the sampling errors in average (over the years and spatially) considering the sampling estimation evaluated by the simulation and the average model biases. "Avg" stands for errors estimated in average over the layer (low, mid or high) while "max" stands for the maximal error detected over one level. $\alpha$ values are the results of section 4.1.1. while $\beta$ values are the results of section 3 .

Table 4: Computing model biases over continent $\left(\alpha=\frac{C F_{W R F+\operatorname{sim}}(z)}{C F_{G O C C P}(z)}\right)$ for low clouds $\left(1\right.$ st row), mid clouds $\left(2^{\text {nd }}\right.$ row) and high clouds ( $3^{\text {rd }}$ row) by testing different undersampling (test 1 means we extract 1 profile over 20 and test 8 means we extract all the profiles). 
884

885

886

887

888

889

890

891

892

893

894

895

896

897

898

899

900

901

902

903

904

905

906

907

908

909

\section{FIGURE CAPTION}

Fig.1 Total area of study with an illustration of the number of CALIPSO overpass in each $20 \times 20 \mathrm{~km}^{2}$ grid-box during one season (here JJA 2008)

Fig.2 Example of a CALIPSO track in 2009/01/19 during night, around $5^{\circ}$ E longitude. (a) SR (z) observed by CALIOP lidar; (b) the total condensed water Q(z) simulated by WRF; (c) SR(z) simulated by WRF using COSP lidar simulator

Fig.3 Simulated cloud vertical profiles cumulated over the entire area of study and averaged over 2006-2011. (a) Summer (JJA), (b) fall (SON), (c) winter (DJF), (d) spring (MAM). Red profiles correspond to simulation with the sampling that follows CALIPSO tracks $\left(\mathrm{CF}_{\mathrm{WRF}+\operatorname{sim}}(\mathrm{z})\right.$ and black profiles are for the entire simulation sampling $\left(\mathrm{CF}_{\mathrm{WRF}+\text { sim }^{\mathrm{T}}}^{\mathrm{T}}(\mathrm{z})\right)$; For each of the subplots, around $4.10^{5}$ profiles have been used to construct the red profiles while $2.10^{6}$ profiles have been used to construct the black ones.

Fig.4 SR(z) histograms cumulated from 2006/06 to 2011/12 for simulation: (a) SR(z) simulation extracted following CALIPSO sampling $\operatorname{SR}_{\mathrm{WRF}+\text { sim }}(\mathrm{z}$ ) in logarithmic scale; (b) same as (a) following WRF sampling $\mathrm{SR}_{\mathrm{WRF}+\mathrm{sim}}(\mathrm{z})$; (c) is (a)-(b); (d) same as (c) only for summers; (e) fall; (f) winter; (g) spring. Colorbars are percentage of the normalized occurrence at each level (the sum of one line is $100 \%$ ). The vertical black lines represent the $\mathrm{SR}=5$ threshold for cloud detection

Fig.5 Seasonal variability of observed and simulated cloud fraction profiles. (a) Mean cloud fraction profile on 2006-2011 for the simulation (blue) and observations (pink) horizontally averaged over the continent; the shades represent the envelope of the four seasons averaged profiles; (b) same as (a) over the sea; (c) Envelope of the seasonal anomaly computed relative to the mean cloud fraction profile over the continent in the simulation (blue shade) in the observations (pink shade); (d) same as (c) over the sea; (e) Mean cloud fraction profile on 20062011 for each season for observations horizontally averaged over the continent; (f) same as (e) over the sea; (g) same as (e) for simulated profiles; (h) same as (g) over the sea. In (e) to (h), blue is for winter, green is for spring, red is for summer, and light blue is for fall

Fig.6 Same as Fig. 4a for observations and simulation in CALIPSO sampling. First column is for observations $\operatorname{SR}_{\mathrm{GOCCP}}(\mathrm{z})$, and second column is for the simulation $\mathrm{SR}_{\mathrm{WRF}+\operatorname{sim}}(\mathrm{z})$. (a) and (b) are for winter, (c) and (d) are for 
spring, (e) and (f) are for summer, (g) and (h) are for fall. Black bars are for the threshold of cloud detection (SR $=5)$. Colorbar is in logarithmic scale

Fig.7 Inter-annual standard deviation of averaged cloud fraction profiles from 2006 to 2011. (a) For winter in the continent; (b) winter in the sea; (c) summer in continent; (d) summer in sea. Pink shade is for observations, blue are for simulation under CALIPSO sampling, and the black line for the simulation in the full sampling. (e) The shade represents $-/+$ the envelope of the standard deviation shown in (a). The blue line is the maximal anomaly values for the simulation. Pink lines are the same as blue lines for observations. (f), (g) and (h) are the same as (e) for winter in the sea, summer in the continent and (d) summer in the sea

Fig.8 CF winter anomaly compared to mean 2007-2011 for different years and altitudes, spatially averaged (a) over the Mediterranean Sea for the simulation from 1989 to 2011; (b) over the Mediterranean Sea for observations from 2007 to 2013; (c) and (d) same as (a)and (b) over the continent

Fig.9 (a) Standard deviation of the simulated $\mathrm{CF}$ value at $\mathrm{z}=9.5 \mathrm{~km}\left(\mathrm{CF}_{9.5}\right)$ computed over the Mediterranean Sea for different number of winters (blue bars). The blue x-axis explains the time period associated to the number of years on which these standard deviations were computed (e.g. the first blue bar is the standard deviation computed over 5 years of simulation and corresponds to the winters 2007 to 2011). The pink bars and pink $\mathrm{x}$-axis are the same as blue bars and blue $\mathrm{x}$-axis but for observations. The blue dots are the $\mathrm{CF}_{9.5}$ winter 2010 anomalies relative to the average $\mathrm{CF}_{9.5}$ computed over the different time periods. Pink dots are the same as blue dots for observations. (b) same as (a) over the continent

Fig.10 Two instantaneous observed SR vertical profiles (blue around $\left[5^{\circ} \mathrm{E} ; 47^{\circ} \mathrm{N}\right]$ and red around $\left[5^{\circ} \mathrm{E} ; 43^{\circ} \mathrm{N}\right]$ ) in 2009/01/19 at night, and vertical black line represents the SR = 5 threshold for cloud detection. Red box in (a) represents the Mediterranean Sea area while the blue box is for Europe area

Fig.11 Winter cloud fraction maps $\left(\mathrm{CF}_{\mathrm{WRF}}{ }^{\mathrm{T}}\right.$ : cloud fraction computed from the model without lidar simulator) averaged from 2006 to 2011 for simulation low clouds (a), mid-clouds (b) and high clouds (c). d, e and f are the same but for summer

Fig.12 Winter 2010 high clouds anomaly computed with $\mathrm{CF}_{\mathrm{WRF}+\mathrm{sim}^{\mathrm{T}}}^{\mathrm{T}}$ relative to the average high cloud map of winters from 1990 to 2011 


\begin{tabular}{|c|c|c|}
\hline & $\begin{array}{l}\text { CALIPSO sampling: using only grid- } \\
\text { boxes along the satellite track }\end{array}$ & $\begin{array}{l}\text { WRF sampling: using all the domain } \\
\text { grid-boxes }\end{array}$ \\
\hline $\begin{array}{c}\text { GOCCP } \\
\text { observations } \\
06 / 2006-12 / 2011\end{array}$ & $\begin{array}{l}S R_{G O C C P}(z) \\
C F_{G O C C P}(z)\end{array}$ & - \\
\hline $\begin{array}{c}\text { WRF simulation }+ \\
\text { COSP simulator } \\
06 / 2006-12 / 2011\end{array}$ & $\begin{array}{l}S R_{W R F+\operatorname{sim}}(z) \\
C F_{W R F+\operatorname{sim}}(z)\end{array}$ & $\begin{array}{l}S R_{W R F+\operatorname{sim}}^{T}(z) \\
C F_{W R F+\operatorname{sim}}^{T}(z)\end{array}$ \\
\hline
\end{tabular}

Table 1: Definition of the datasets used for the study. Columns define the sampling method. Lines stand for the product used. SR is the scattering ratio measured by the lidar (annex 1) and CF is the percentage of clouds per gridbox.

\section{1}

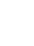

4

\section{5}

\section{6}




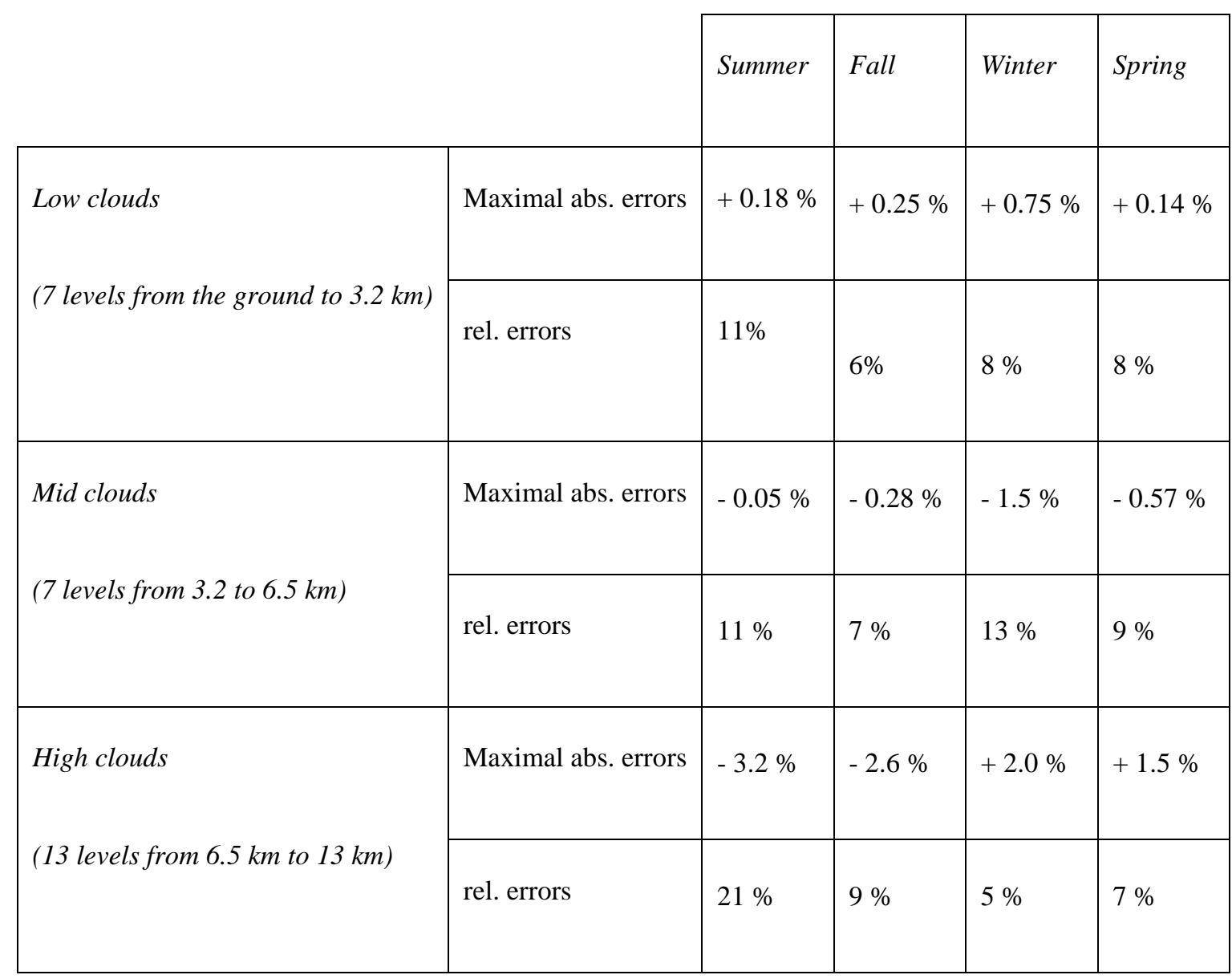

Table 2: Maximal differences (i.e. absolute - “abs.” - errors) between simulated cloud fractions extracted with 


\begin{tabular}{|c|c|c|c|}
\hline & $\begin{array}{c}\text { CF Relative } \\
\text { model bias } \\
\alpha=\frac{C F_{W R F+\operatorname{sim}}}{C F_{G O C C P}}\end{array}$ & $\begin{array}{c}\text { CALIPSO undersampling error estimated by } \\
\text { simulated cloud fraction } \\
\beta=\left|C F_{W R F+\operatorname{sim}}-C F_{W R F+\operatorname{sim}}^{T}\right|\end{array}$ & $\varepsilon=\frac{\beta}{\alpha}$ \\
\hline Low clouds & 0.36 & $A v g=0.15 \% ; \max =0.33 \%$ & $A v g=0.4 \% ; \max =0.9 \%$ \\
\hline Mid clouds & 0.43 & $A v g=0.4 \% ; \max =0.6 \%$ & $A v g=0.9 \% ; \max =1.4 \%$ \\
\hline High clouds & 2.32 & $A v g=1.4 \% ; \max =2.35 \%$ & $A v g=0.6 \% ; \max =1 \%$ \\
\hline
\end{tabular}

Table 3: Estimation of the sampling errors in average (over the years and spatially) considering the sampling estimation evaluated by the simulation and the average model biases. "Avg" stands for errors estimated in average over the layer (low, mid or high) while "max" stands for the maximal error detected over one level. $\alpha$ values are the results of section 4.1.1. while $\beta$ values are the results of section 3. 


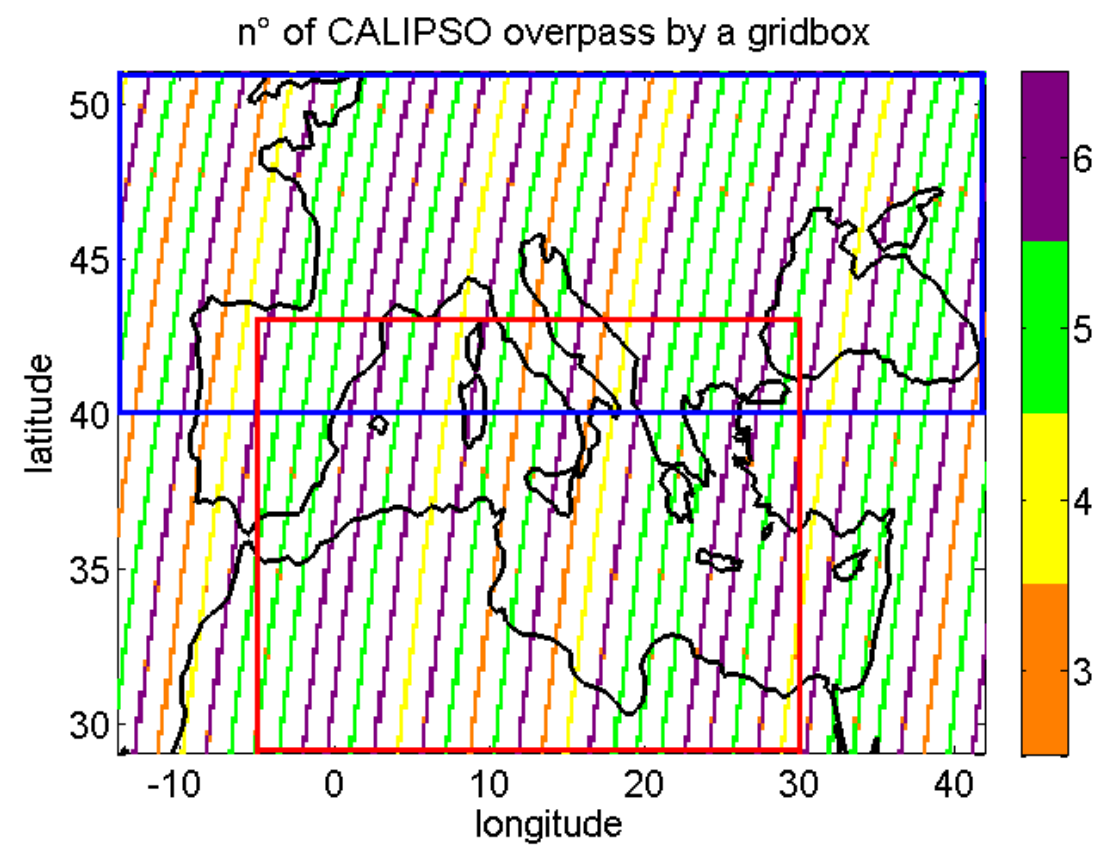

Fig.1 Total area of study with an illustration of the number of CALIPSO overpass in each $20 \times 20 \mathrm{~km}^{2}$ grid-box

during one season (here JJA 2008) 
a. $\mathrm{SR}_{\mathrm{GOCCP}}(\mathbf{z})$

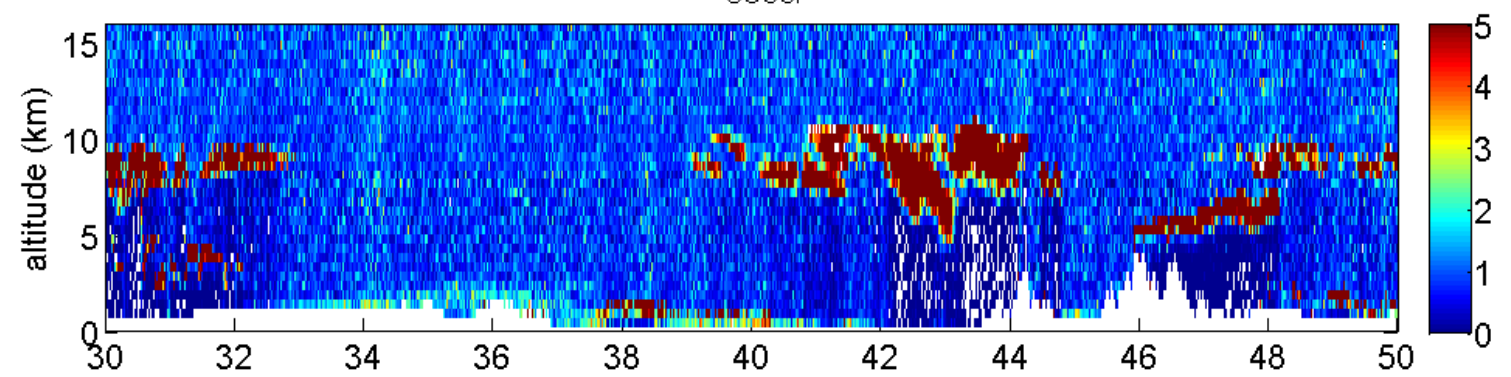

b. $Q_{\text {WRF }}(z)$
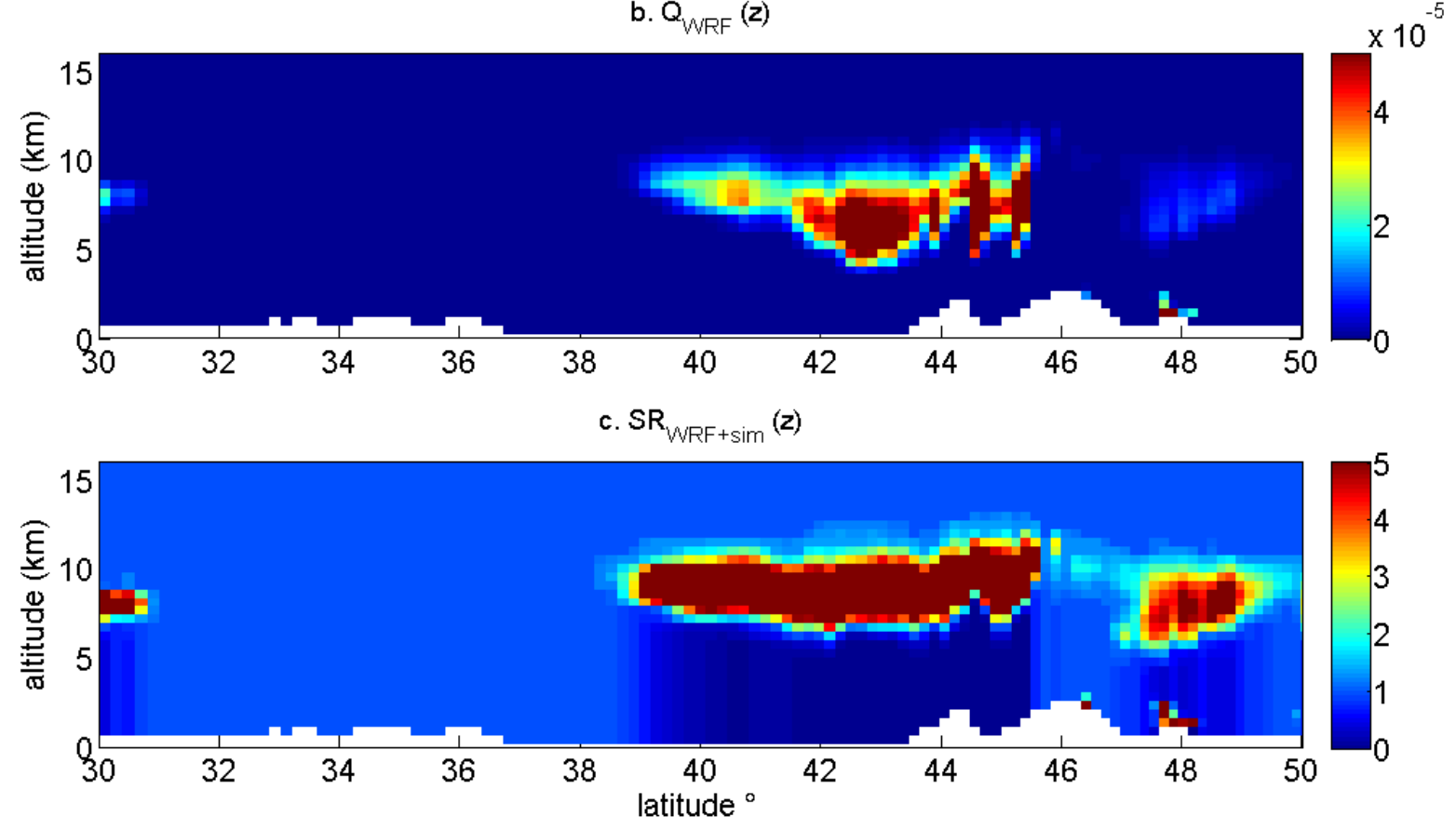

971 Fig.2 Example of a CALIPSO track in 2009/01/19 during night, around $5^{\circ} \mathrm{E}$ longitude. (a) SR (z) observed by

973 CALIOP lidar; (b) the total condensed water Q(z) simulated by WRF; (c) SR(z) simulated by WRF using COSP lidar simulator 

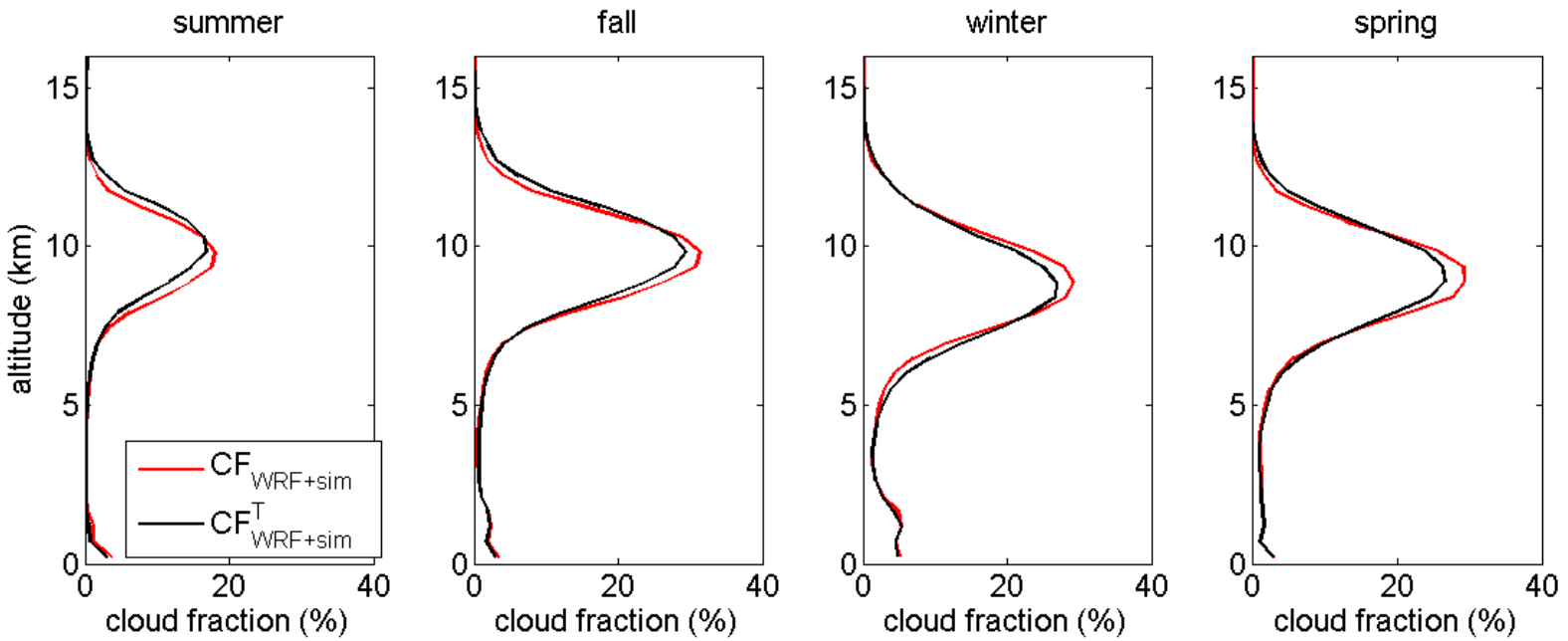

Fig.3 Simulated cloud vertical profiles cumulated over the entire area of study and averaged over 2006-2011. (a)

Summer (JJA), (b) fall (SON), (c) winter (DJF), (d) spring (MAM). Red profiles correspond to simulation with the sampling that follows CALIPSO tracks $\left(\mathrm{CF}_{\mathrm{WRF}+\mathrm{sim}}(\mathrm{z})\right)$ and black profiles are for the entire simulation sampling $\left(\mathrm{CF}_{\mathrm{WRF}+\operatorname{sim}}^{\mathrm{T}}(\mathrm{z})\right)$; For each of the subplots, around $5.10^{4}$ profiles have been used to construct the red profiles while $2.10^{6}$ profiles have been used to construct the black ones. 

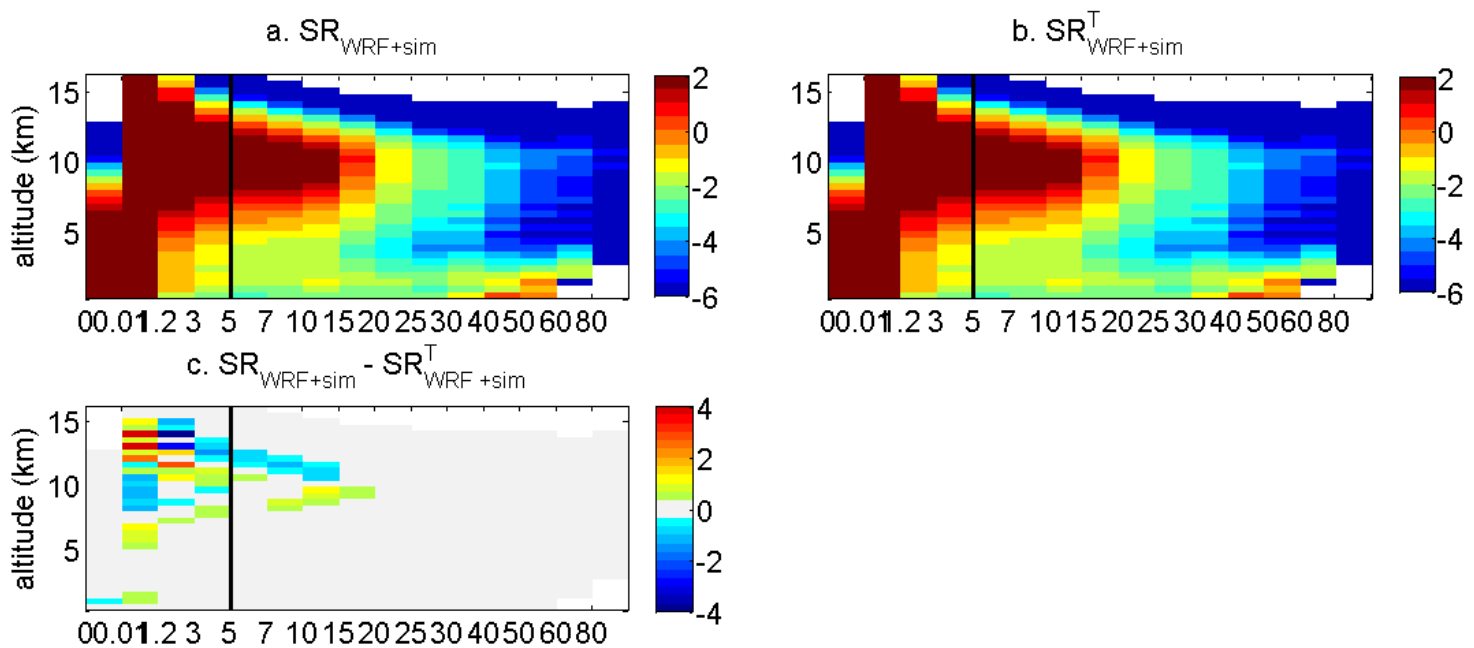

d. summer
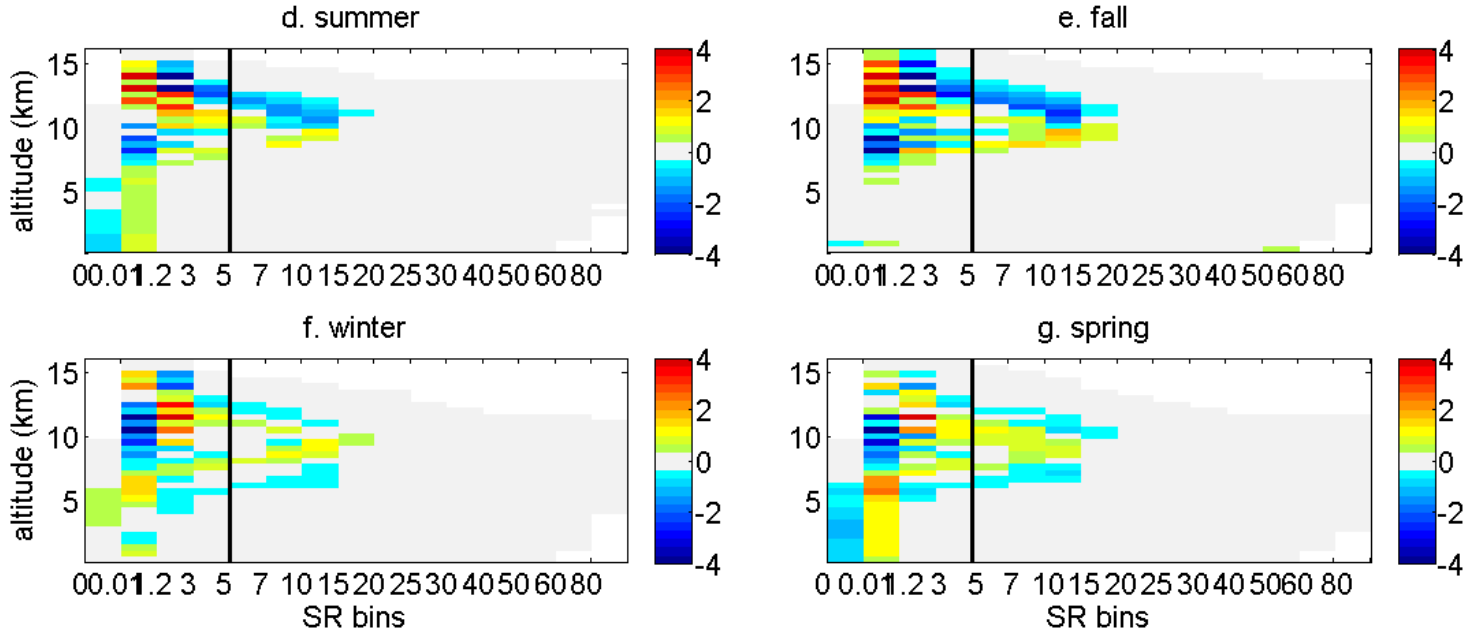

Fig.4 SR(z) histograms cumulated from 2006/06 to 2011/12 for simulation: (a) SR(z) simulation extracted following CALIPSO sampling $\mathrm{SR}_{\mathrm{WRF}+\text { sim }}(\mathrm{z})$ in logarithmic scale; (b) same as (a) following WRF sampling $\mathrm{SR}_{\mathrm{WRF}+\text { sim }}(\mathrm{z})$; (c) is (a)-(b); (d) same as (c) only for summers; (e) fall; (f) winter; (g) spring. Colorbars are percentage of the normalized occurrence at each level (the sum of one line is $100 \%$ ). The vertical black lines represent the $\mathrm{SR}=5$ threshold for cloud detection 

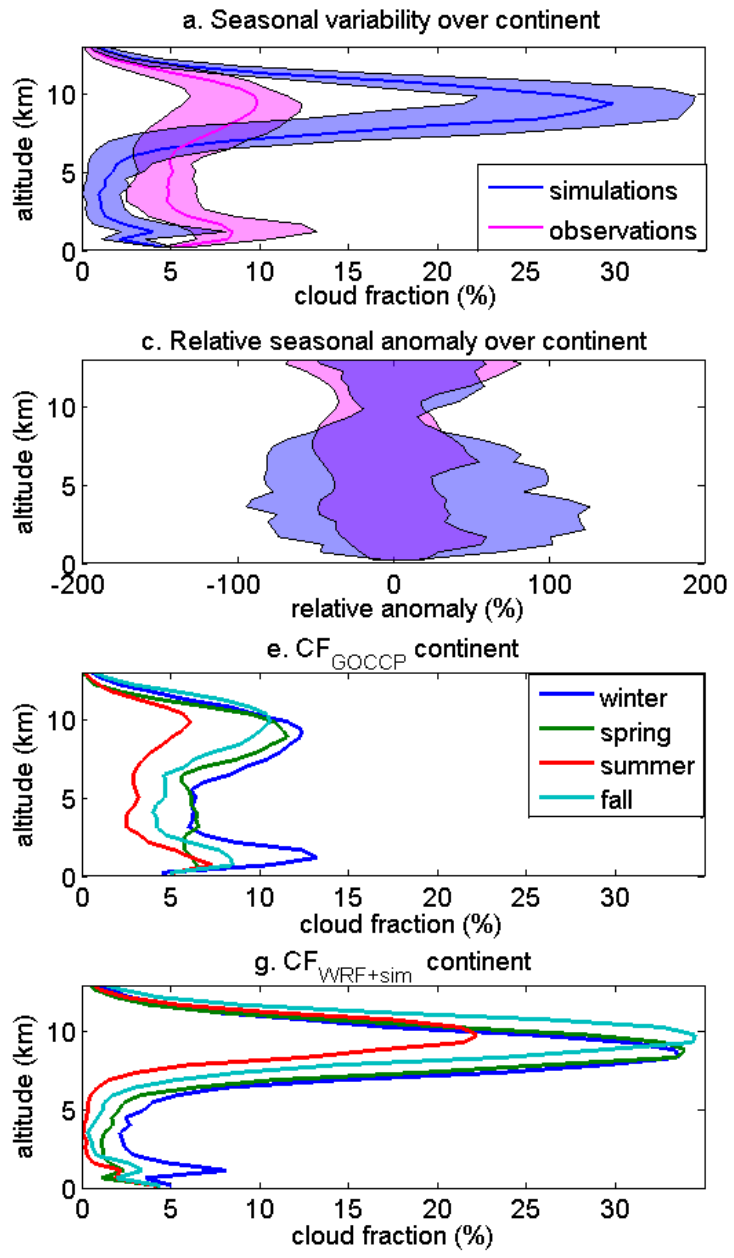

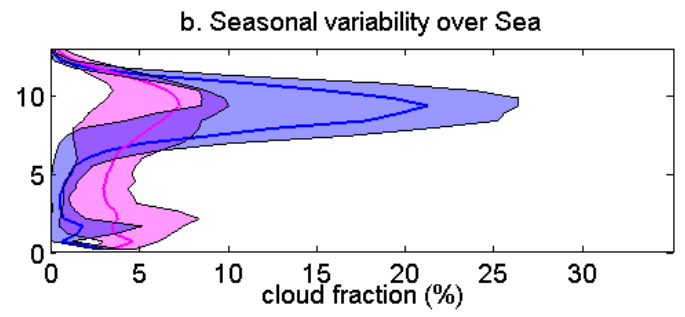

d. Relative seasonal anomaly over sea

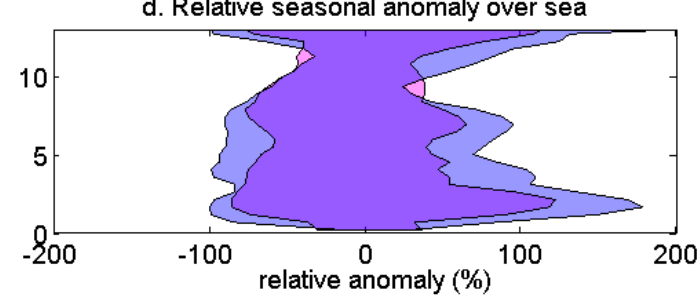

f. $\mathrm{CF}_{\mathrm{GoCCP}}$ sea

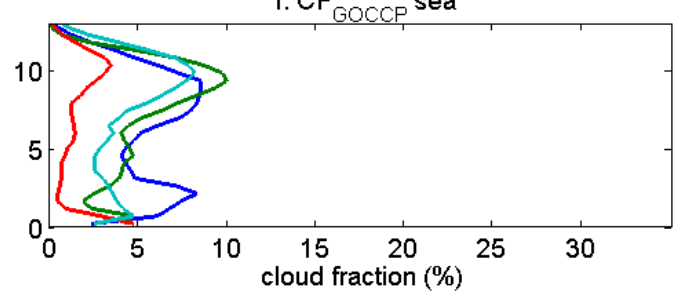

h. CF WRF+sim $_{\text {sea }}$

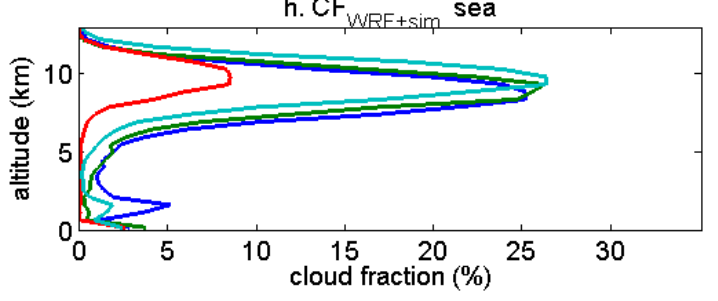

Fig.5 Seasonal variability of observed and simulated cloud fraction profiles. (a) Mean cloud fraction profile on 2006-2011 for the simulation (blue) and observations (pink) horizontally averaged over the continent; the shades represent the envelope of the four seasons averaged profiles; (b) same as (a) over the sea; (c) Envelope of the seasonal anomaly computed relative to the mean cloud fraction profile over the continent in the simulation (blue shade) in the observations (pink shade); (d) same as (c) over the sea; (e) Mean cloud fraction profile on 20062011 for each season for observations horizontally averaged over the continent; (f) same as (e) over the sea; (g) same as (e) for simulated profiles; (h) same as (g) over the sea. In (e) to (h), blue is for winter, green is for spring, red is for summer, and light blue is for fall 
a. $\operatorname{SR}_{\mathrm{GOCCP}}(\mathbf{z})$ winter

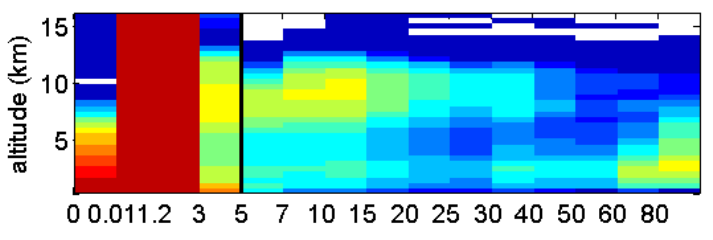

c. $\mathrm{SR}_{\mathrm{GOCCP}}(\mathrm{z})$ spring

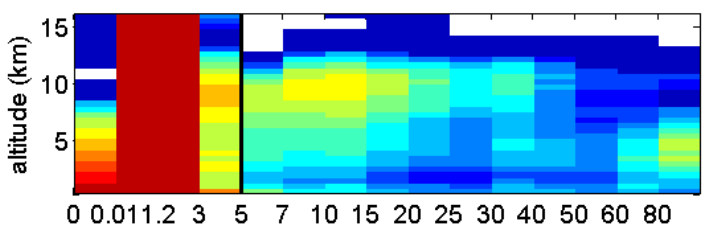

e. $\mathrm{SR}_{\mathrm{GOCCP}}(\mathrm{z})$ summer

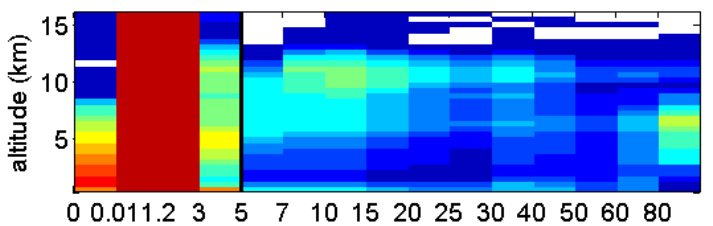

g. $\operatorname{SR}_{\mathrm{GOCCP}}(\mathbf{z})$ fall

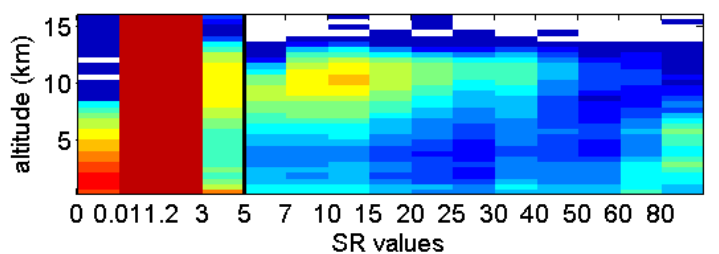

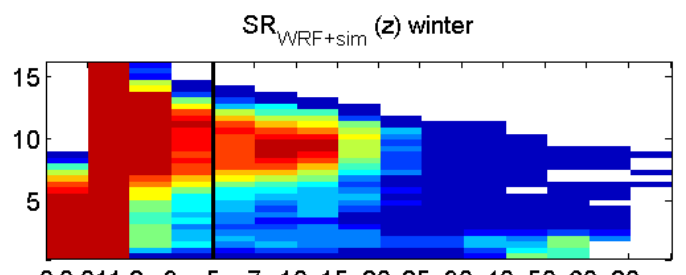

$00.011 .2 \quad 3 \quad 5 \quad 7 \quad 101520253040 \quad 5060 \quad 80$ $\mathrm{SR}_{\text {WRF+sim }}$ (z) spring

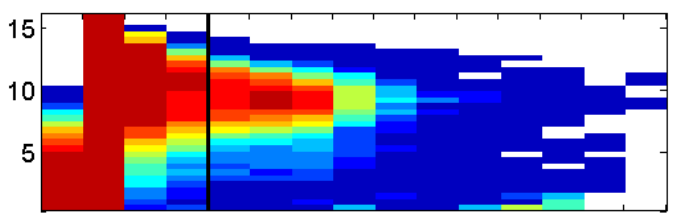

$00.011 .23 \quad 5 \quad 7 \quad 101520253040506080$ $\mathrm{SR}_{\text {WRF+sim }}$ (z) summer

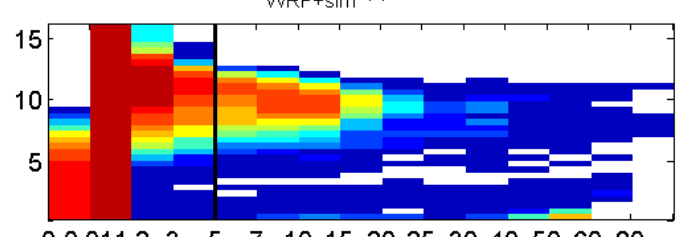

$00.011 .23 \quad 5 \quad 7 \quad 101520253040 \quad 506080$ $\mathrm{SR}_{\text {WRF+sim }}(\mathbf{z})$ fall

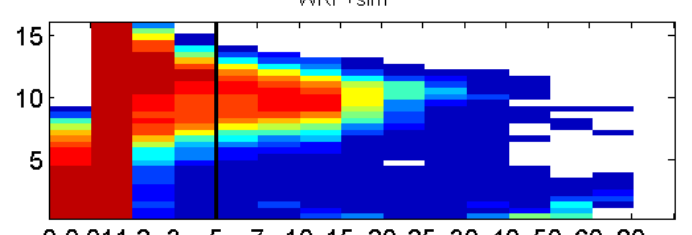

00.011 .235577101520253040506080 SR occurrence (\%) SR values

Fig.6 Same as Fig. 4a for observations and simulation in CALIPSO sampling. First column is for observations 

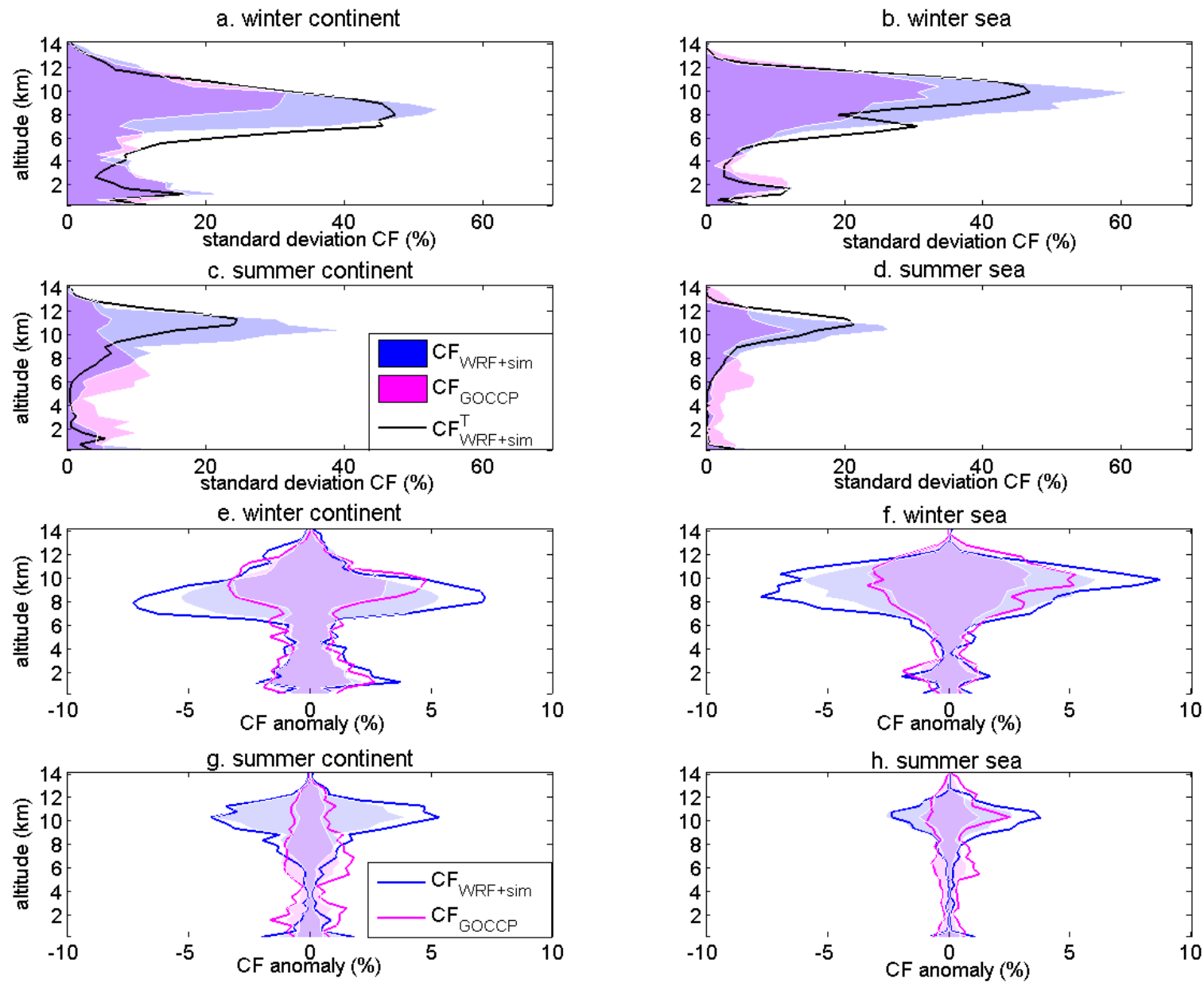

Fig.7 Inter-annual standard deviation of averaged cloud fraction profiles from 2006 to 2011. (a) For winter in the continent; (b) winter in the sea; (c) summer in continent; (d) summer in sea. Pink shade is for observations, blue are for simulation under CALIPSO sampling, and the black line for the simulation in the full sampling. (e) The shade represents $-/+$ the envelope of the standard deviation shown in (a). The blue line is the maximal anomaly values for the simulation. Pink lines are the same as blue lines for observations. (f), (g) and (h) are the same as (e) for winter in the sea, summer in the continent and (d) summer in the sea 

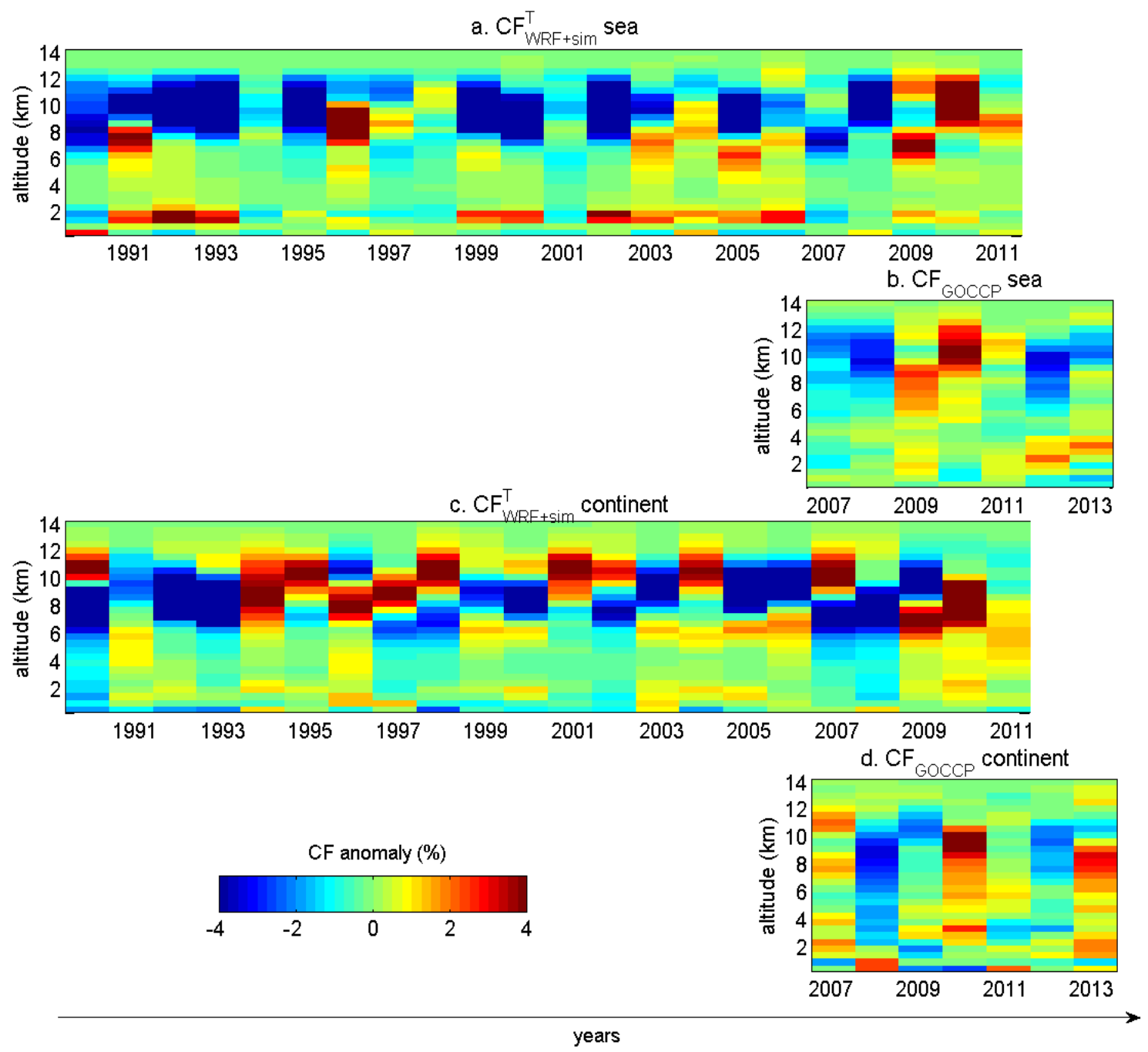

1015 Fig.8 CF winter anomaly compared to mean 2007-2011 for different years and altitudes, spatially averaged (a)

1016 over the Mediterranean Sea for the simulation from 1989 to 2011; (b) over the Mediterranean Sea for 1017 observations from 2007 to 2013; (c) and (d) same as (a)and (b) over the continent 
a. sea

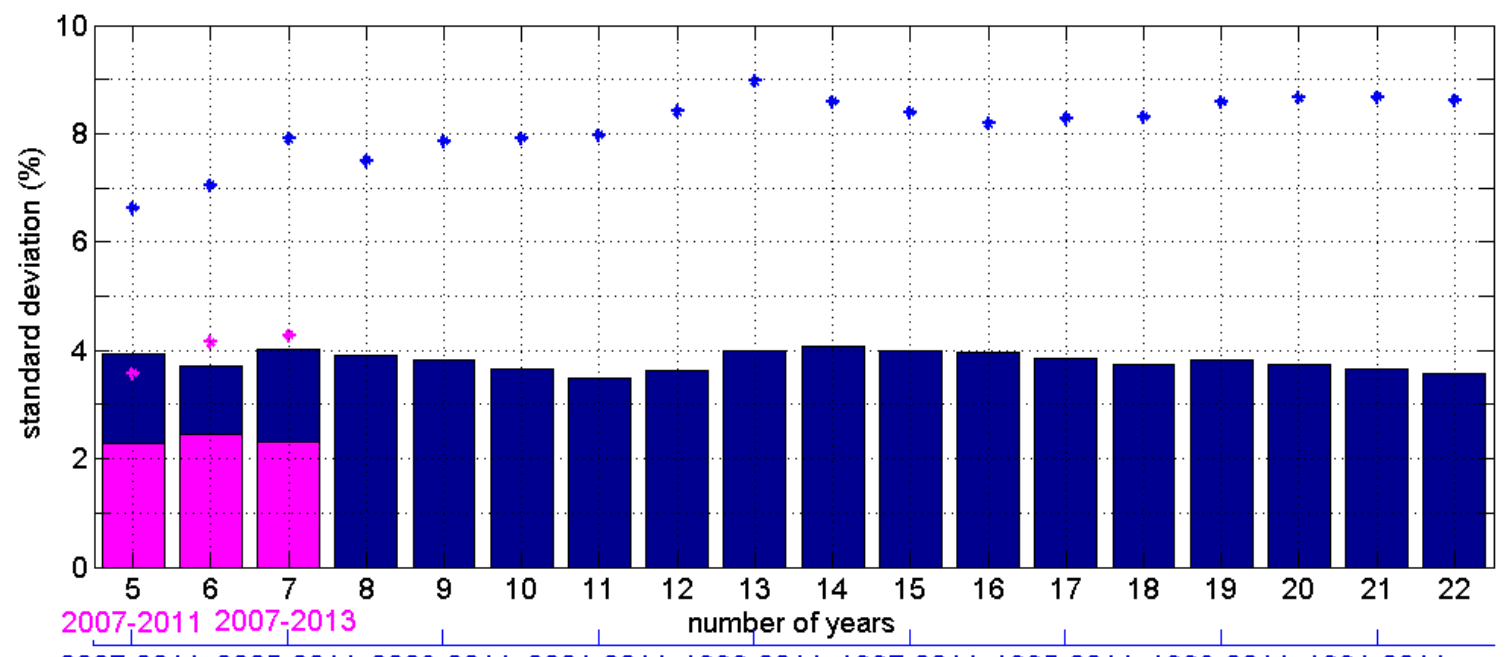

2007-2011 2005-2011 2003-2011 2001-2011 1999-2011 1997-2011 1995-2011 1993-2011 1991-2011

time period

b. continent

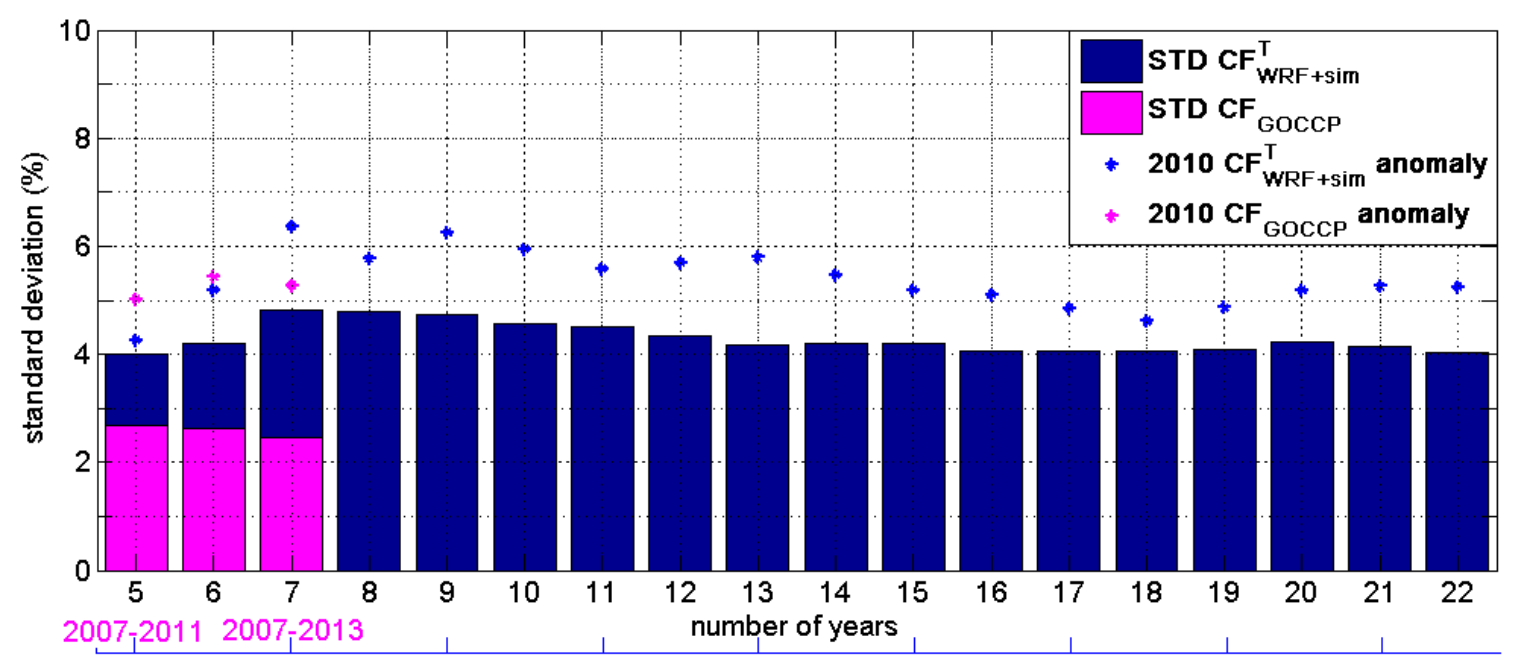

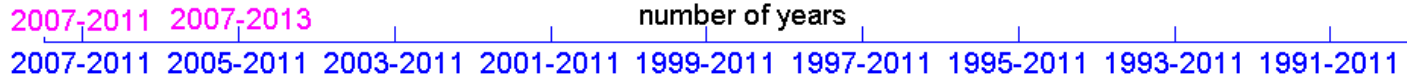

Fig.9 (a) Standard deviation of the simulated $\mathrm{CF}$ value at $\mathrm{z}=9.5 \mathrm{~km}\left(\mathrm{CF}_{9.5}\right)$ computed over the Mediterranean

Sea for different number of winters (blue bars). The blue $\mathrm{x}$-axis explains the time period associated to the number of years on which these standard deviations were computed (e.g. the first blue bar is the standard deviation computed over 5 years of simulation and corresponds to the winters 2007 to 2011). The pink bars and pink $\mathrm{x}$-axis are the same as blue bars and blue $\mathrm{x}$-axis but for observations. The blue dots are the $\mathrm{CF}_{9.5}$ winter 2010 anomalies relative to the average $\mathrm{CF}_{9.5}$ computed over the different time periods. Pink dots are the same as blue dots for observations. (b) same as (a) over the continent 


\section{Annex 1: Lidar equation}

The scattering ratio SR is given by (1):

$S R(z)=\frac{A T B_{t o t}(z)}{A T B_{m o l}(z)}(1)$

Where $A T B_{\text {tot }}$ and $A T B_{m o l}$ are respectively the attenuated backscattered signals for particles and molecules and for molecules only and are given by (2) and (3):

$\operatorname{ATB}_{\text {tot }}(z)=\left(\beta_{\text {sca,part }}(z)+\beta_{\text {sca,mol }}(z)\right) \cdot e^{-2 \eta \int_{z_{T O A}}^{z}\left(\alpha_{\text {sca,part }}(z)+\alpha_{\text {sca,mol }}(z)\right) \cdot d z}(2)$

$A T B_{m o l}(z)=\beta_{s c a, m o l}(z) \cdot e^{-2 \eta \int_{z_{T O A}}^{z} \alpha_{s c a, m o l}(z) \cdot d z}(3)$

$\mathrm{ATB}_{\text {mol }}$ and $\mathrm{ATB}_{\text {tot }}$ products are averaged vertically to obtain SR over 40 layers (Chepfer et al. 2008 and 2010).

$\beta_{\text {sca,part }}, \beta_{\text {sca,mol }}$ are lidar backscatter coefficients $\left(\mathrm{m}^{-1} \mathrm{sr}^{-1}\right)$ and $\alpha_{\text {sca,part }}$ and $\alpha_{\text {sca,mol }}$ attenuation coefficients $\left(\mathrm{m}^{-1}\right)$ for particles (clouds, aerosols) and molecules. $\eta$ is a multiple scattering coefficient that depends both on lidar characteristics and size, shape and density of particles. It is about 0.7 for CALIPSO (Winker et al., 2003; Chepfer et al., 2008).

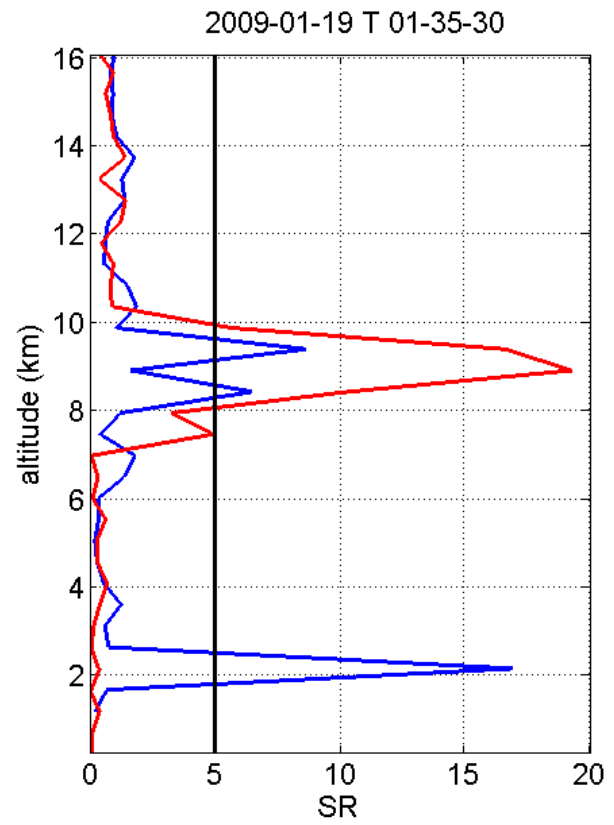

Fig.10: Two instantaneous observed SR vertical profiles (blue around $\left[5^{\circ} \mathrm{E} ; 47^{\circ} \mathrm{N}\right]$ and red around $\left[5^{\circ} \mathrm{E} ; 43^{\circ} \mathrm{N}\right]$ ) in 2009/01/19 at night. The vertical black line represents the SR = 5 threshold for cloud detection. 
Figure 10 illustrates two instantaneous SR profiles to help understand what a lidar signal looks like and how cloud detection is computed in this study. Above $10 \mathrm{~km}, \mathrm{SR}(\mathrm{z})$ is around 1, indicating clear sky for both profiles. High clouds are detected in both profiles between $8 \mathrm{~km}$ and $10 \mathrm{~km}$ : SR(z) of the blue profile reaches the value of 8 and while $\operatorname{SR}(z)$ of the red one goes up to 22. The magnitude of SR(z) depends on the cloud optical thickness from the Top Of Atmosphere (TOA) to the level $\mathrm{z}$ and the cloud microphysical properties such as the size of the particle or its shape. While the signal is fully attenuated for the red profile below $8 \mathrm{~km}(\mathrm{SR}(\mathrm{z})$ is almost zero), the blue profile still detects low clouds around $2 \mathrm{~km}$.

\section{Annex 2: Simulated cloud fraction maps}
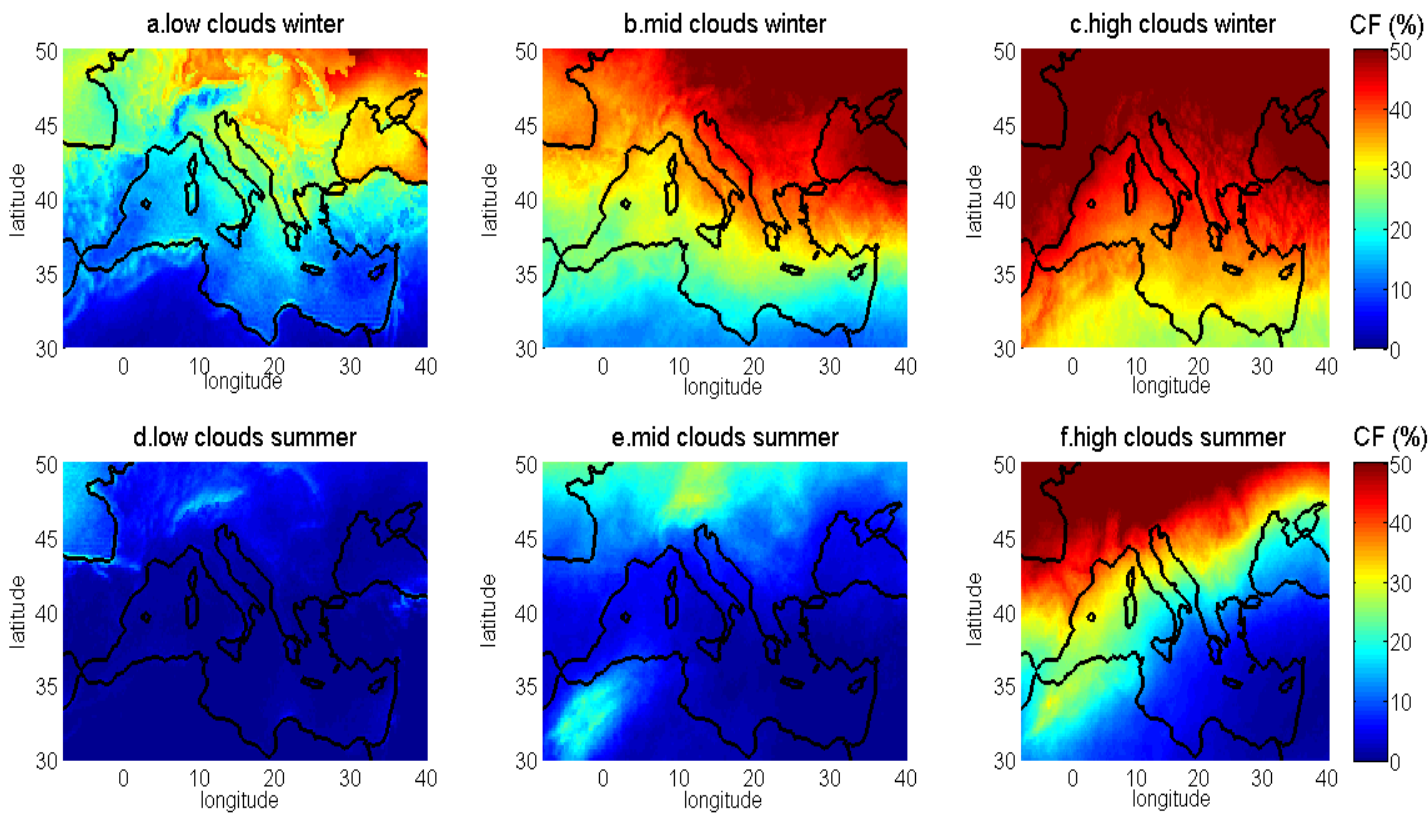

Fig.11 Winter cloud fraction maps (cloud fraction computed from the model without lidar simulator) averaged from 2006 to 2011 for simulation low clouds (a), mid-clouds (b) and high clouds (c). d, e and f are the same but for summer

Fig.11 shows that: for high clouds, a north-south gradient exists in winter with about $10 \%$ of clouds over North Africa and more than 50\% above continental Europe, while in summer, this gradient is north-west/south-east, with almost no high clouds over Turkish and eastern part of Mediterranean basin. In winter, most mid and low clouds occur above the north-eastern part of Europe. In summer, very few mid and low clouds are simulated and they are mostly induced by orography.

\section{Annex 3: Simulated winter 2010 high clouds anomaly}




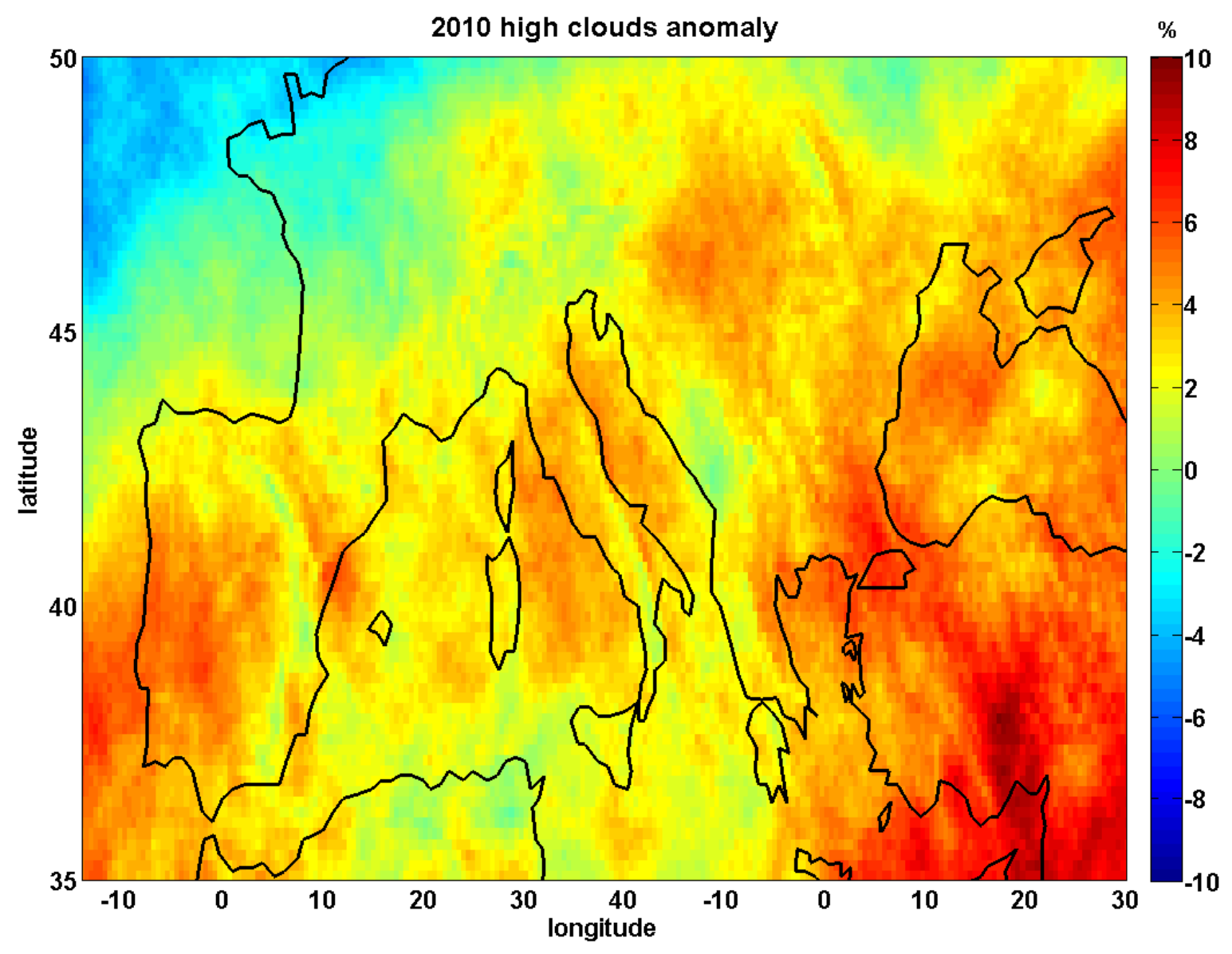

1061

1062

Fig12 Winter 2010 high clouds anomaly computed with $\mathrm{CF}_{\mathrm{WRF}+\operatorname{sim}}{ }^{\mathrm{T}}$ relative to the average high cloud map of 1063 winters from 1990 to 2011

1064

1065

1066

1067

1068

1069 Annex 4:

1070

The CALIPSO undersampling error estimation from observed cloud fraction profiles is defined as:

1071

$\varepsilon(z)=\left|C F_{G O C C P}(z)-C F_{G O C C P}^{T}(z)\right|$ with $C F_{G O C C P}^{T}(z)$ a theoretical cloud fraction that we would have with a complete sampling (observations over all the grid-boxes every 00UTC). 
1073

1074

1075

1076

1077

1078

1079

1080

1081 undersampling estimated by the simulation.

\begin{tabular}{|l|l|l|l|l|l|l|l|l|}
\hline Sampling & Test 1 : & Test 2: & Test 3 : & Test 4: & Test 5 : & Test 6: & Test 7 : & Test 8 : \\
& $1 / 20$ & $1 / 15$ & $1 / 10$ & $1 / 5$ & $1 / 4$ & $1 / 3$ & $1 / 2$ & $1 / 1$ \\
\hline low & 0.29 & 0.43 & 0.38 & 0.38 & 0.4 & 0.36 & 0.37 & 0.36 \\
\hline mid & 0.5100 & 0.4700 & 0.4000 & 0.4000 & 0.4200 & 0.4200 & 0.4300 & 0.4300 \\
\hline high & 7.9400 & 2.3300 & 2.4000 & 2.1900 & 2.3300 & 2.3500 & 2.3300 & 2.3200 \\
\hline
\end{tabular}

We define $\alpha(z)$ as the relative model bias, so $\alpha(z)=\frac{C F_{W R F+\operatorname{sim}}(z)}{C F_{G O C C P}(z)}$

We used a set of different samplings to test if $\alpha(z)$ can be considered as constant, i.e independent of the number of profiles in the sampling. To do that, since we need both observations and simulation to test this hypothesis, we reduced the CALIPSO sampling using only 1 profile over 2 (test 7), 1 over 3 (test 6), and so on down to one profile over 20. Table 4 presents the results of these tests and indicates the a values for low, mid and high clouds. This shows that if the number of profiles become greater than 1/15 of the CALIPSO sampling, $\alpha(z)$ can be considered as nearly constant.

We deduce that: $\alpha(z)=\frac{C F_{W R F+\operatorname{sim}}^{T}(z)}{C_{G O C C P}^{T}(z)}$

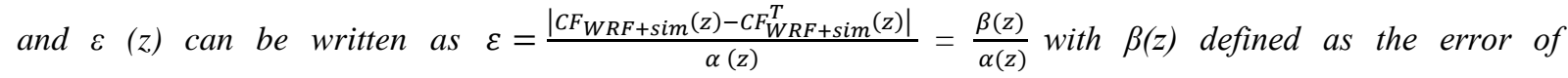

Table 4: computing model biases over continent $\left(\alpha=\frac{C F_{W R F+\operatorname{sim}}(z)}{C F_{G O C C P}(z)}\right)$ for low clouds (1st row), mid clouds ( $2^{\text {nd }}$ row) and high clouds $\left(3^{\text {rd }}\right.$ row) by testing different samplings (test 1 means we extract 1 profile over 20 and test 8 means we extract all the profiles). 